\title{
Covariance of Optimal Parameters of an Arctic Sea Ice-Ocean Model ${ }^{\mathscr{}}$
}

\author{
HiRoshi Sumata \\ Alfred-Wegener-Institut Helmholtz-Zentrum für Polar- und Meeresforschung, Bremerhaven, Germany \\ FRANK KAUKER AND MiCHAEL KARCHER \\ Alfred-Wegener-Institut Helmholtz-Zentrum für Polar- und Meeresforschung, Bremerhaven, and \\ Ocean Atmosphere Systems, Hamburg, Germany \\ RÜDIGER GERDES \\ Alfred-Wegener-Institut Helmholtz-Zentrum für Polar- und Meeresforschung, Bremerhaven, and \\ Jacobs University, Bremen, Germany
}

(Manuscript received 23 October 2018, in final form 3 May 2019)

\begin{abstract}
The uniqueness of optimal parameter sets of an Arctic sea ice simulation is investigated. A set of parameter optimization experiments is performed using an automatic parameter optimization system, which simultaneously optimizes 15 dynamic and thermodynamic process parameters. The system employs a stochastic approach (genetic algorithm) to find the global minimum of a cost function. The cost function is defined by the model-observation misfit and observational uncertainties of three sea ice properties (concentration, thickness, drift) covering the entire Arctic Ocean over more than two decades. A total of 11 independent optimizations are carried out to examine the uniqueness of the minimum of the cost function and the associated optimal parameter sets. All 11 optimizations asymptotically reduce the value of the cost functions toward an apparent global minimum and provide strikingly similar sea ice fields. The corresponding optimal parameters, however, exhibit a large spread, showing the existence of multiple optimal solutions. The result shows that the utilized sea ice observations, even though covering more than two decades, cannot constrain the process parameters toward a unique solution. A correlation analysis shows that the optimal parameters are interrelated and covariant. A principal component analysis reveals that the first three (six) principal components explain $70 \%(90 \%)$ of the total variance of the optimal parameter sets, indicating a contraction of the parameter space. Analysis of the associated ocean fields exhibits a large spread of these fields over the 11 optimized parameter sets, suggesting an importance of ocean properties to achieve a dynamically consistent view of the coupled sea ice-ocean system.
\end{abstract}

\section{Introduction}

Sea ice is one of the most distinctive features of the Arctic climate system. Although sea ice forms on a thin solid layer of a few meters thick, it substantially modulates heat, freshwater, and momentum exchanges between the atmosphere and the ocean (Wadhams 2002; McPhee 2008; Thomas and Dieckmann 2009).

Supplemental information related to this paper is available at the Journals Online website: https://doi.org/10.1175/MWR-D-180375.s1.

Corresponding author: Hiroshi Sumata, hiroshi.sumata@awi.de
Improvement of dynamic and thermodynamic processes in sea ice models thus constitutes an important part of climate modeling and a prerequisite for meaningful predictions. Comprehensive large-scale sea ice models have been developed and applied to a variety of climate studies over more than three decades (Hunke et al. 2010), while even current models differ in the simulated sea ice properties and exhibit pronounced biases in comparison with observations (Rothrock et al. 2003; Stroeve et al. 2007, 2012; Uotila et al. 2019). Ceaseless efforts to improve parameterizations of physical processes in sea ice models are ongoing (e.g., Tsamados et al. 2013; Juricke et al. 2013; Ungermann et al. 2017). Such efforts concurrently involve explorations of optimal 
parameters for corresponding parameterizations and model configurations (e.g., Miller et al. 2006; Nguyen et al. 2011; Urrego-Blanco et al. 2016; Docquier et al. 2017).

An exploration of optimal parameters for a certain model configuration comprises an important part of the model development (Holland et al. 1993; Chapman et al. 1994; Kim et al. 2006). An implementation of new physical schemes, for example, requires the reexamination of all relevant parameters (e.g., Massonnet et al. 2011), since the optimality of individual parameters depends on the other parameters (Chapman et al. 1994). Reexaminations are also necessary when the atmospheric forcing data is altered or updated, since the model's process parameters partly compensate for biases in the forcing (Miller et al. 2007; Eisenman et al. 2007). The introduction of new observational data products, in addition, offers opportunities for further refinement of physical processes and concurrent re-examinations of all relevant parameters. For these reasons efficient and automated parameter optimization methodologies have been developed, which optimize many model parameters simultaneously [see Sumata et al. (2019) for a survey on the methods].

Parameter optimizations can be systematically achieved by data assimilation procedures (Nguyen et al. 2011; Massonnet et al. 2014; Sumata et al. 2013, 2019). Data assimilation synthesizes observed data and model physics based on statistical theories (Wunsch 2006; Blayo et al. 2015). In these applications, a control vector composed of model parameters is optimized to minimize a model-observation misfit with an assessment of errors of the observation and the model (evaluation of a cost function). Nguyen et al. (2011) optimized 13 model parameters, initial and boundary conditions using the Green's function approach. Although they did not examine the optimality of the solution, they reported a successful reduction of the cost function. Massonnet et al. (2014) applied the ensemble Kalman filter (EnKF) method to optimize three dynamic model parameters, and reported a large reduction of bias in the ice drift speed. Sumata et al. (2013) compared the efficiency of two different optimization methods for seven parameters; the gradient descent and the genetic algorithm. The study showed the advantage of stochastic approaches (e.g., genetic algorithm) for an exploration of the global minimum of a structurally complex cost function, in comparison with the gradient descent approach. Sumata et al. (2019) applied the genetic algorithm for a simultaneous optimization of 15 model parameters over a multidecadal time window. They reported that the optimized parameter set improves the simulated climatology and interannual variation of sea ice extent, thickness and drift, simultaneously.

Although many studies on parameter optimizations have been performed in recent years, a fundamental question remains unanswered; "Is the optimal parameter set a unique solution?". In the frame work of data assimilation, a parameter optimization is a search problem of the global minimum of a cost function. Since even a single model parameter strongly influences modeled sea ice properties, a combination of many parameters gives rise to a complex structure of the cost function. Multivariate parameter sensitivity studies revealed complex features of the cost functions and associated difficulties of defining a unique set of optimal parameters; Harder and Fischer (1999) reported an elliptical shape with significant eccentricity of the cost function in a two-dimensional parameter space, which indicate a counteracting effect of two parameters on the cost function; Miller et al. (2006) showed that two sea ice properties (sea ice extent and velocity) are not sufficient to unambiguously define a unique set of optimal parameters; Hunke (2010) reported that multiple combinations of parameter values result in the same mean ice thickness using the Los Alamos Sea Ice Model. These studies imply the existence of multiple solutions of the optimization problem.

In the following study, we investigate the uniqueness of the optimal solution obtained from an automatic parameter optimization system applied for an Arctic sea ice-ocean model. The study utilizes the optimization system applied in Sumata et al. (2019) and investigates the spread of optimized sea ice variables and associated parameters by a set of independent optimizations. The system employs a microgenetic aAlgorithm (mGA) for the search, which is shown in Sumata et al. (2013) to be less prone to end up in local minima in contrast to gradient descent approaches. We show that 1) a sea ice-ocean model constrained by widely used observed sea ice properties has a unique solution with regard to the simulated sea ice fields, whereas 2) the associated optimal parameter sets give multiple solutions with a large spread, and finally 3) the optimal parameters have interdependencies which reduce the dimension of the parameter space. The potential of additional ocean observations providing further constraints on the parameters will be discussed in conjunction with an analysis of the associated ocean fields. The paper is organized as follows: section 2 describes the methodology and experiment design, section 3 describes the result of the optimizations and the covariance of the optimal parameters, section 4 discusses the results, and section 5 contains concluding remarks. 


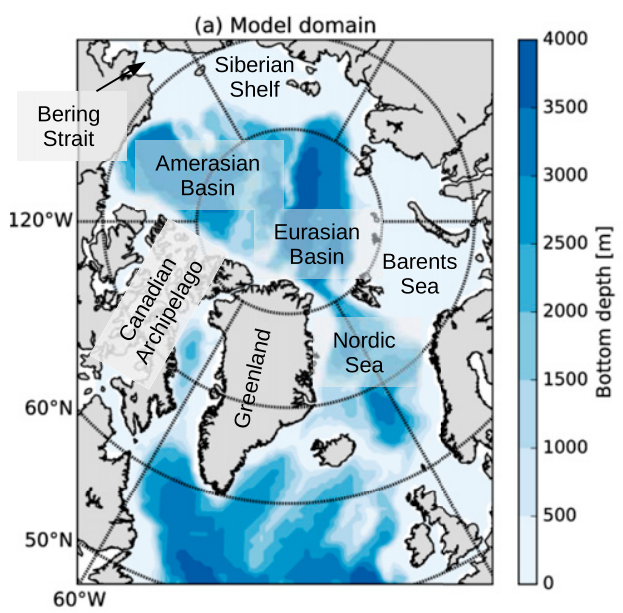

(b) Sketch of the time line of the model simulations

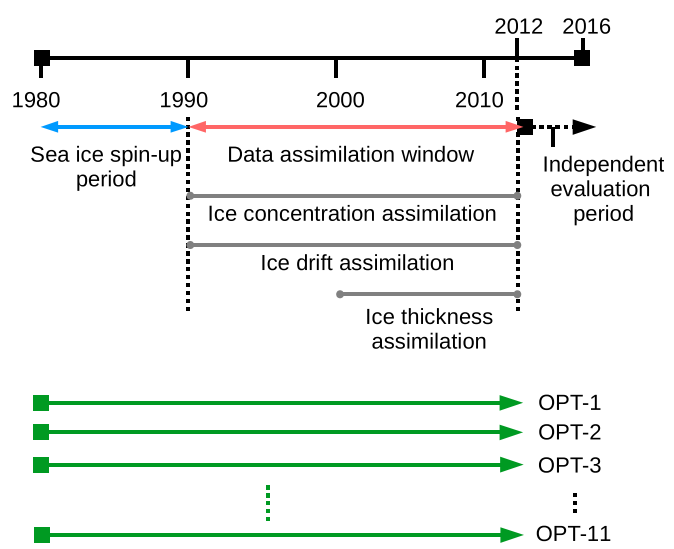

FIG. 1. (a) Model domain including names of locations mentioned in the main text. (b) Sketch of the time line of the model simulations for the parameter optimizations.

\section{Experiment design}

\section{a. Coupled ocean-sea ice model}

We use a parameter optimization system developed by Sumata et al. (2019). The system applies a regional sea ice-ocean model of the Arctic and northern North Atlantic Ocean [North Atlantic/Arctic Ocean Sea Ice Model (NAOSIM)] developed at the Alfred Wegener Institute (Gerdes et al. 2003; Kauker et al. 2003, 2009; Karcher et al. 2007, 2012) for the optimization. The sea ice model employs the viscous plastic (VP) rheology (Hibler 1979; Harder 1996) with a zero-layer thermodynamic formulation (Semtner, 1976). The dynamic and thermodynamic schemes are implemented based on Owens and Lemke (1990) with additional modifications (e.g., a ridging process; Flato and Hibler 1991, and a subgrid-scale parameterization of ice thickness; CastroMorales et al. 2014). A complete set of dynamic and thermodynamic equations of the sea ice model is provided in Sumata et al. (2019). The ocean model is based on the Modular Ocean Model, version 2 (MOM-2), developed at the Geophysical Fluid Dynamics Laboratory (Pacanowski 1995), and coupled with the sea ice model following Hibler and Bryan (1987). The model domain is formulated on a spherical rotated grid covering the whole Arctic and the North Atlantic Ocean north of approximately $50^{\circ} \mathrm{N}$ (Fig. 1a). The geographical North Pole is shifted to $60^{\circ} \mathrm{E}$ on the equator to ensure nearly equidistant grid cells over the domain. We employ a low-resolution version of NAOSIM (Kauker et al. 2009), with a horizontal resolution of $55 \mathrm{~km} \times$ $55 \mathrm{~km}$. The ocean model has 20 levels in the vertical: the thickness of the top five layers are $20 \mathrm{~m}$ and they gradually increase to $605 \mathrm{~m}$ at the deepest level (Sumata et al. 2013).
An open boundary condition has been implemented along the Atlantic sector of the model domain following Stevens (1991). In the Pacific sector the Bering Strait is treated as a closed wall. Temperature and salinity at inflow points of the Atlantic sector are restored toward the Polar Science Center's Hydrographic Climatology (PHC; Steele et al. 2001). The barotropic velocities normal to the boundary are given by a model version covering the entire Arctic and Atlantic Ocean north of $20^{\circ} \mathrm{S}$ (Köberle and Gerdes 2003). The initial condition (in January 1980) of the optimization experiments is derived from a 32-yr integration (1948-80) with NCEP-NCAR reanalysis forcing (Kalnay et al. 1996) starting from temperature and salinity fields given by the PHC climatology and $100 \%$ sea ice concentration with a thickness of $2 \mathrm{~m}$ in regions where the sea surface temperature falls below the freezing point of seawater. The model is driven by daily $10-\mathrm{m}$ surface wind, 2-m air temperature, 2-m specific humidity, downward longwave and shortwave radiation, and total precipitation from NCEP's Climate Forecast System Reanalysis (NCEP CFSR; Saha et al. 2010) for the period 1980-2010 and from NCEP's Climate Forecast System, version 2 (CFSv2; Saha et al. 2014), for the period 2011-16.

\section{b. Model parameters selected for optimization}

We optimize 15 sea ice and ocean model parameters (Table 1). The dynamic parameters of the sea ice model are: ice compressive strength constant, $P^{*}$; wind and water drag coefficients, $C_{\mathrm{dwin}}$ and $C_{\mathrm{dwat}}$; ice strength decay constant, $C^{*}$; eccentricity of the yield curve describing the VP-rheology, $e$. The ice strength constant $\left(P^{*}\right)$ and the drag coefficients $\left(C_{\mathrm{dwin}}\right.$ and $\left.C_{\mathrm{dwat}}\right)$ are the 
TABLE 1. Dynamic and thermodynamic model parameters applied for the optimization.

\begin{tabular}{|c|c|c|c|c|c|}
\hline Name & Short description & Lower bound & Upper bound & Increment & CTRL run \\
\hline$h_{0}$ & $\begin{array}{l}\text { Demarcation thickness between thin and thick } \\
\text { ice for ice compactness equation }(\mathrm{m})\end{array}$ & 0.1 & 1.0 & $8.798 \times 10^{-4}$ & 0.5 \\
\hline$P^{*}$ & Ice compressive strength constant $\left(\mathrm{N} \mathrm{m}^{-2}\right)$ & $1.0 \times 10^{4}$ & $5.0 \times 10^{4}$ & $3.91 \times 10$ & $2.5 \times 10^{4}$ \\
\hline$C_{\mathrm{dwin}}$ & Wind drag coefficient & $0.5 \times 10^{-3}$ & $2.5 \times 10^{-3}$ & $1.955 \times 10^{-6}$ & $1.1 \times 10^{-3}$ \\
\hline$C_{\mathrm{dwat}}$ & Water drag coefficient & $3.5 \times 10^{-3}$ & $8.5 \times 10^{-3}$ & $4.888 \times 10^{-6}$ & $5.5 \times 10^{-3}$ \\
\hline$C_{\text {lat }}$ & Latent heat transfer coefficient & $1.0 \times 10^{-3}$ & $2.5 \times 10^{-3}$ & $1.466 \times 10^{-6}$ & $1.75 \times 10^{-3}$ \\
\hline$C_{\text {sens }}$ & Sensible heat transfer coefficient & $1.25 \times 10^{-3}$ & $2.5 \times 10^{-3}$ & $1.222 \times 10^{-6}$ & $1.75 \times 10^{-3}$ \\
\hline$\alpha_{s}$ & Snow albedo & 0.65 & 0.95 & $2.933 \times 10^{-4}$ & 0.8 \\
\hline$\alpha_{\mathrm{sm}}$ & Albedo of melting snow & 0.65 & 0.95 & $2.933 \times 10^{-4}$ & 0.77 \\
\hline$\alpha_{i}$ & Ice albedo & 0.65 & 0.95 & $2.933 \times 10^{-4}$ & 0.65 \\
\hline$\alpha_{\mathrm{im}}$ & Albedo of melting ice & 0.65 & 0.95 & $2.933 \times 10^{-4}$ & 0.68 \\
\hline$C^{*}$ & Ice strength decay constant & 5.0 & 20.0 & $1.466 \times 10^{-2}$ & 10.0 \\
\hline$C_{\text {melt }}$ & $\begin{array}{l}\text { Area melting constant for ice compactness } \\
\text { equation }\end{array}$ & 0.1 & 1.0 & $8.798 \times 10^{-4}$ & 0.5 \\
\hline$\alpha_{w}$ & Albedo of seawater & 0.05 & 0.45 & $3.91 \times 10^{-4}$ & 0.1 \\
\hline$\kappa_{H}$ & Oceanic vertical diffusion coefficient $\left(\mathrm{cm}^{2} \mathrm{~s}^{-1}\right)$ & 0.0 & 1.0 & $9.775 \times 10^{-4}$ & 0.0 \\
\hline$e$ & $\begin{array}{l}\text { Eccentricity of the yield curve describing the } \\
\text { viscous-plastic rheology }\end{array}$ & 1.5 & 2.3 & $7.82 \times 10^{-4}$ & 2.0 \\
\hline
\end{tabular}

key tuning parameters to obtain a realistic horizontal sea ice distribution. Explorations of optimal values or appropriate ranges of these parameters have been made in a number of studies (e.g., Chapman et al. 1994; Harder and Fischer 1999; Massonnet et al. 2014) including application of stochastic parameterization approach (Juricke et al. 2013; Brankart et al. 2015). The ice strength decay constant $\left(C^{*}\right)$ defines the exponential decay of the ice strength with decreasing ice concentration. Since $C^{*}$ represents unresolved subgrid-scale sea ice interaction, it is also considered as a tuning parameter (Holland et al. 1993; Dumont et al. 2009). The eccentricity of the yield curve $(e)$, defining the ratio between the compressive and shear stress strength, is an empirical constant which can be tuned to reproduce a realistic horizontal pattern of sea ice thickness especially north of Greenland (e.g., Miller et al. 2005; Bouchat and Tremblay 2017).

The thermodynamic parameters are: snow and sea ice albedo for freezing and melting conditions $\left(\alpha_{s}\right.$, $\left.\alpha_{\mathrm{sm}}, \alpha_{i}, \alpha_{\mathrm{im}}\right)$; latent and sensible heat transfer coefficients, $C_{\text {lat }}$ and $C_{\text {sens }}$; demarcation thickness between thin and thick ice, $h_{0}$; and the area melting constant for the ice compactness equation, $C_{\text {melt }}$. The sea ice and snow albedo are the key parameters regulating the heat budget of the model. The optimal values for various formulation have been examined by many studies (e.g., Kim et al. 2006; Miller et al. 2006, 2007; Uotila et al. 2012). The latent and sensible heat transfer coefficients are also important parameters regulating the thermodynamic equations (Sumata et al. 2013). The demarcation thickness between thin and thick ice, $h_{0}$, which appears in the sea ice compactness equation, defines the thickness of newly formed ice under freezing condition. Since it parameterizes the unresolved sea ice formation processes, $h_{0}$ is considered as one of the tuning parameters for realistic simulations (e.g., Nguyen et al. 2011). The area melting constant for the compactness equation $\left(C_{\text {melt }}\right)$ is introduced to parameterize the subgridscale sea ice thickness distribution (Castro-Morales et al. 2014). The term $C_{\text {melt }}$ is a unitless parameter and relates the ice thickness reduction to the ice concentration reduction.

Two parameters are taken from the ocean part of the model; the albedo of seawater, $\alpha_{w}$, and the oceanic vertical diffusion coefficient, $\kappa_{H}$ (the full value of the vertical diffusion in the model except convection and numerical diffusion). The albedo of seawater is a key parameter representing unresolved ice-albedo feedback processes. The vertical diffusion coefficient, $\kappa_{H}$, describes the heat exchange between the mixed layer and the stratified ocean layers, which has a substantial effect on the melting and growth of sea ice.

\section{c. Observational data}

We apply basin-wide observations of three sea ice properties for the optimization: concentration, thickness and drift. The concentration dataset is the lowresolution sea ice concentration product, OSI-409/ OSI-409a (version 1.2; Eastwood et al. 2017), provided by the European Organisation for the Exploitation of Meteorological Satellites (EUMETSAT) Ocean and Sea Ice Satellite Application Facility (OSI SAF). The dataset provides sea ice concentration over the entire 
Arctic Ocean with a horizontal resolution of $10 \mathrm{~km}$, including associated errors. The temporal coverage of the dataset is $1978-2015$. We average the daily data to monthly mean data on the model grid to facilitate the cost function calculation described in section $2 \mathrm{~d}$. We define the error of the monthly mean sea ice concentration by the average of the error of the daily data as a tentative approach, since the temporal error covariance is not known for the time being. The monthly mean sea ice concentration and the errors are applied for 23 years (1990-2012) to define the cost function.

For the thickness observation we apply the sea ice thickness estimate of Lindsay and Schweiger (2015). Their estimate is based on a least squares multiple regression model (Ice Thickness Regression Procedure or ITRP; Rothrock et al. 2008). Lindsay and Schweiger (2015) utilized a variety of sea ice thickness measurements (upward-looking sonars, electromagnetic sensors, lidar and radar altimeters) and provided a comprehensive ice thickness estimate covering the Arctic basin for the period 2000-12 with associated errors of the regression. Since lower-order polynomials are applied in space and time, the thickness estimate is spatially and temporally smoothed, and does not contain interannual variability but contains the long-term trend. For the time being, the thickness from ITRP, taking all available sources for ice thickness for the time period 2000-12 into account, is considered as the most reliable Arctic-wide dataset covering more than a decade. Since ITRP is not representing all scales of spatial and temporal variations due to the used regression to low-order polynomials in space and time, it should be used with some caution. We calculate monthly mean thickness and associated errors based on the regression model, and apply a sea ice area mask taken from the ICESat thickness product (Kwok et al. 2009) to exclude the area not covered by any input data for the regression (e.g., south of Fram Strait). We also exclude thickness estimates for summer months (JuneSeptember) to avoid constraining the model by erroneous thickness estimates in summer. In the ITRP thickness estimate, the maximum thickness occurs in June, which is presumably an artifact coming from the regression procedure with few input data in summer. Thickness from 13 years (2000-12) is used for the implementation of the cost function.

The ice drift data are taken from three different products covering the entire Arctic Ocean 1) OSI-405: Lavergne et al. (2010), 2) the sea ice motion estimate by Kimura et al. 2013, and 3) the Polar Pathfinder Daily $25 \mathrm{~km}$ EASE-Grid Sea Ice Motion Vectors, version 2 (hereafter referred to as NSIDCv2; Tschudi et al. 2010; Fowler et al. 2013). The three products have different advantages and weaknesses (Sumata et al. 2014). OSI-405 gives the smallest uncertainty among the three products, while the temporal coverage is limited (after 2002, without summer months). The sea ice motion estimate by Kimura et al. (2013) covers the same period as OSI-405, but includes the summer months as well. NSIDCv2 gives the largest uncertainty among the products (Sumata et al. 2015a, b), while it covers the entire period of the satellite operation (1978-the present). To take the full advantage of the three products, we combined them. OSI-405 is employed when available, missing summer months are covered by ice motion estimate from Kimura et al. (2013). The rest of the period (before 2002 and missing data period in 2011 and 2012) is covered by NSIDCv2. Although such a combination of different products results in a limited improvement of the simulated sea ice drift due to difference of error statistics (Sumata et al. 2019), it is the only possible way to cover the multidecadal optimization window. We calculate monthly mean drift from the combined dataset and implement the cost function with associated error and bias (Sumata et al. 2015b) for 1990-2012. More comprehensive description of the data products can be found in Sumata et al. (2019).

\section{d. Cost function}

As a quantitative measure of a model-observation misfit, we introduce the cost function,

$$
J=\frac{1}{2}[\mathbf{d}-\mathbf{b}-H(\mathbf{p})]^{\mathrm{T}} \mathbf{R}^{-1}[\mathbf{d}-\mathbf{b}-H(\mathbf{p})],
$$

where $\mathbf{d}=\left[d_{1}, d_{2}, \ldots, d_{N}\right]^{\mathrm{T}}$ is the observation vector comprising monthly mean value of observed concentration, thickness and drift at each model grid point in each month (section $2 c), \mathbf{b}=\left[b_{1}, b_{2}, \ldots, b_{\mathrm{N}}\right]^{\mathrm{T}}$ is the bias vector (defined for drift only), $\mathbf{p}=\left[p_{1}, p_{2}, \ldots, p_{15}\right]^{\mathrm{T}}$ is the control vector composed of the 15 model parameters (section 2b), $H$ is the model (section $2 \mathrm{a}$ ), which maps the control vector to modeled monthly mean sea ice quantities, and $\mathbf{R}$ is the uncertainty covariance matrix of observational data. The superscript $\mathrm{T}$ denotes a matrix transpose. Since spatial and temporal correlation of the observational errors are not known, we assume that the errors are uncorrelated (i.e., only the diagonal elements of the matrix $\mathbf{R}$ are considered). The contributions from the respective quantities in the cost function are normalized by those calculated from a reference experiment (a control run, described in section 2f), that is, the total cost function $(J)$ for the control run is 3.0 , with a contribution from the respective sea ice quantities of 1.0. The normalization is introduced to realize the equal contribution from the three sea ice quantities (otherwise 
the sea ice concentration has a dominating effect in the cost function due to the smallest relative uncertainty among the three quantities and the largest length in time of the three datasets), while we are aware that the normalization increases the subjectivity of the method. The minimum value of the cost function is examined by the method described in section $2 \mathrm{e}$.

Unlike the cost functions used for a state estimation and/or initial/boundary condition optimizations, the cost takes neither model error nor a prior term into account. The omission of the model error attributes the model-observation misfit to imperfections in parameter values exclusively, while the exclusion of the prior term makes it possible to explore the entire parameter space without preferring 'physical' or empirical values. The estimated parameters are "optimal" in the sense that they minimize the model-observation misfit regardless of potential deficiencies in the modeling system [i.e., the values of optimal parameters may depend on the shortcomings of the model physics (parameterization/resolution) and biases in the forcing dataset (NCEP CFSR has known biases, see e.g., Lindsay et al. 2014)]. This may result in optimal parameters outside the range of values suggested by in situ observation or physical reasoning, but helps us to identify model processes and/or surface boundary conditions which need further refinement and improvement (Sumata et al. 2019).

\section{e. Genetic algorithm}

The minimum of the cost function is explored by a microgenetic algorithm (mGA). Genetic algorithms (GAs) are a class of heuristic optimization algorithms based on the natural selection of living things (Holland 1975; Goldberg 1989), and mGA is a small population version of the GAs (Krishnakumar 1989; Athias et al. 2000). In comparison with steep-gradient descent approaches, GAs are less prone to get stuck at local minima during the search of the global minimum of an objective (cost) function. This is a clear advantage when dealing with cost functions which have potentially a complicated structure such as in this study. The GAs, on the other hand, require a large amount of computational resources compared to nonheuristic approaches. The normal GAs need a population size of $O\left(10^{4}\right)$ to retain a sufficient amount of genetic information (potential of parameter combinations in the present case). Since the population size is the number of required model runs, GAs need $O\left(10^{4}\right)$ parallel model runs and subsequent cost function evaluations for each iteration-which is not practical if a general circulation model is applied for the cost function assessment. The mGA, on the other hand, employs very small population size, generally fewer than 10 (Coello and Pulido 2001; Athias et al. 2000; Kim et al. 2002; Sumata et al. 2013).

The basic idea behind the mGA is to combine two minimum search strategies in order to achieve a fast convergence for small population sizes. The first strategy is to search in the parameter space composed of a small number of possibilities. As a result of the small population size, the convergence of the solution occurs very quickly (normally within fewer than 10 generations), although the estimate of the minimum is not accurate due to the limited coverage of the full parameter space. The second strategy is to perform a global search by iterative reinitializations. A reinitialization consecutively expands the search space by introducing new individuals. Since the fittest individual (i.e., the best parameter set from the first strategy) is involved in the reinitialized generation, the convergence occurs toward the solution with the fittest individual, if no new minimum is found. This procedure ensures iterative and intensive search around the local minimum and complements the rough estimate by the first strategy [see appendix A in Sumata et al. (2013) for an example].

The mGA minimize the cost function by the following procedure. 1) Prepare a prescribed number (population size) of individuals. The genotype of each individual represents a single set of model parameters. This is realized by encoding the control vector to a binary bit string. When starting an optimization, random numbers are used to generate the initial individuals. 2) Perform an assessment of fitness of each individual. This is achieved by a model run with a certain set of parameters and a subsequent model-observation misfit assessment by the cost function. 3) Perform a selection. The fittest individual (i.e., the control vector which gives the smallest value of the cost function) is retained, and other individuals are dismissed. 4) Prepare a new generation. The fittest individual from the previous generation enters automatically. Other individuals are generated by the random combinations of two individuals from the previous generation, including the fittest. In this generational process, the bit strings representing the genotypes of the two individuals are randomly merged. Since the fittest individual always participates in the random selection of the two individuals, it influences the direction of the evolution. 5) Assess the convergence of the genotype of the current generation. If the difference between the genotypes is smaller than a prescribed threshold, a reinitialization is performed. The reinitialization removes all individuals except the fittest and introduces new individuals, the genotypes of which are generated by random numbers. 
The fittest automatically survives and enters the next generation. If the difference between the genotypes is larger than the threshold, repeat steps $2-4$ in the process. More comprehensive description of the $\mathrm{mGA}$ and its practical implementation to a parameter optimization of general circulation models can be found in Sumata et al. (2013, 2019).

The possible ranges of the respective parameters are prescribed by upper and lower bounds (Table 1). The definition of the bounds are based on the results of previous studies and physical constraints (e.g., negative values are not allowed, albedo should be smaller than 1). The respective parameter ranges are discretized in 512 values (i.e., a parameter value is represented by a genotype with a length of 9 bits). The discretization increments for the respective parameters are shown in Table 1 as well. As a whole the mGA explores a parameter space composed of 15 parameters with 512 possible values for each parameter (approximately $4.36 \times 10^{40}$ possible combinations in total). We use a population size of 6 (the number of individuals for each generation) which is motivated by our previous study (Sumata et al. 2013). The generation size (number of iterations) is 1000 , which is sufficient to obtain a convergence of the solution as shown in this study (section 3a).

\section{f. Optimization experiments}

We conduct a set of 11 independent optimizations to explore the solutions of the system. Each optimization starts from a randomly chosen parameter set, in which a different seed for the generation of the random numbers are used. This means each optimization carries out a search of the minimum cost from a different starting point and therefore with a different search path. In the following section an optimal parameter set and associated sea ice field obtained from $n$th optimization are referred to as "OPT- $n$ " $(n=1,2, \ldots$, 11 ), and the whole 11 optimizations are referred to as "11-OPTs".

The model is integrated for 33 years (1980-2012, Fig. 1b). The first 10 years of the window (1980-89) are considered as a spinup time necessary for the adaptation of the sea ice properties to the tested parameters and therefore we exclude this period from the cost function calculation. The full seasonal cycle of the observed sea ice concentration and ice drift (section 2c) are applied in the following 23 years (19902012), while the ice thickness is only used in the last 13 years (2000-12) with the exception of the summer months (July-September). Note that although the cost function assesses the model-observation misfit for the 1990-2012 period, the control vector (i.e., an optimized parameter set) changes ice fields over the entire integration window.

In addition to the optimization experiments, we conduct a reference model run (a control run, hereafter CTRL), for which the standard parameter values for the model (Sumata et al. 2013) are used (Table 1). The cost calculated from CTRL is used as a reference to evaluate a reduction of the cost by the optimizations. As a total, 2.18 million model-year integrations are carried out (population size of 6 times 1000 generations times 11 independent optimizations with 33-yr model integration window $=2.18 \times 10^{6} \mathrm{yr}$ ).

\section{Result}

\section{a. Spread of simulated optimized sea ice variables}

All the optimizations successfully reduce asymptotically the value of the cost functions (herein called "costs" for brevity) toward almost the same value (Fig. 2a). Large reductions of the costs occur in the first 50 generations and the reduction rate decreases strongly for subsequent generations (Fig. 2b). The reduction of the cost after the 200th generation is already very small and the parameter sets taken from this generation are of practical use (i.e., can be considered to have been converged). Since further (tiny) reductions hardly occur in the cost nor spread after the 600th generation (Fig. 2c), we stop the optimizations at the 1000th generation and apply the corresponding sea ice fields and estimated parameter sets (control vectors) for the following analyses. Hereafter we define "spread" by the difference between the maximum and minimum value of 11-OPTs for any quantity.

\section{1) SeA ICE CONCENTRATION AND EXTENT}

All optimizations successfully reduce the cost of the concentration term in the cost function and improve both the seasonal cycle and the interannual variations of the sea ice extent (Fig. 3). The spread of the seasonal cycle and the interannual variability of the sea ice extent in 11-OPTs (orange shade in Fig. 3) is more than one order of magnitude smaller than the interannual variations of the extent and is comparable to the model-observation misfit, both in winter and summer. Figure 3 also shows a clear reduction of Integrated Ice-Edge Error (IIEE; Goessling et al. 2016) both in seasonal cycle (Fig. 3c) and interannual variation (Fig. 3d). IIEE is the sum of over and underestimates of ice covered area $(>15 \%)$ in comparison with the observation. In contrast to the sea ice extent, IIEE quantifies the mismatch of the location of sea ice 
(a) Evolution of cost function

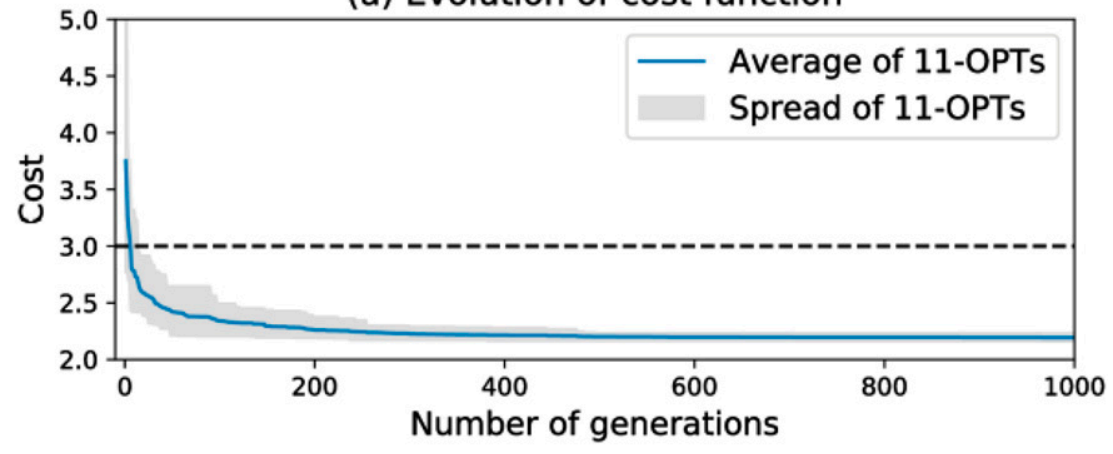

(b) Reduction rate of cost function

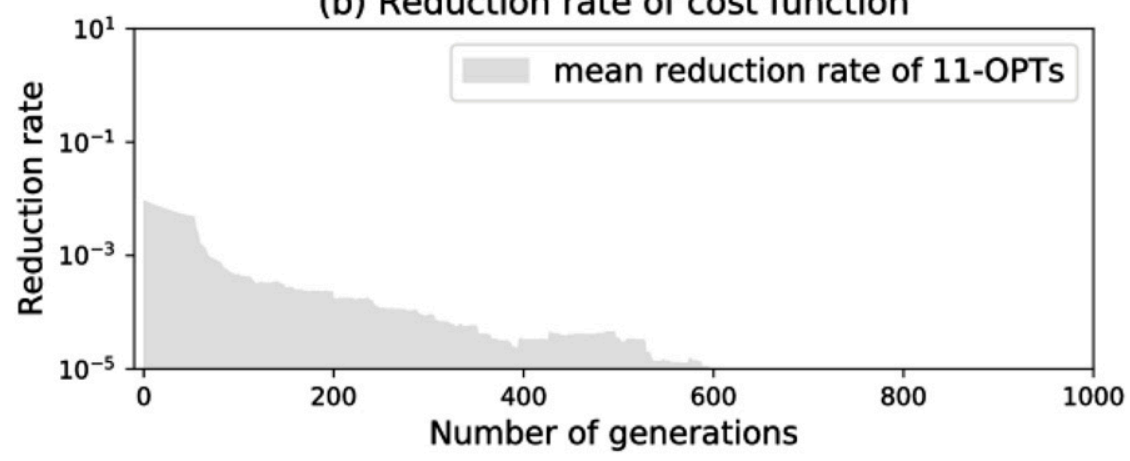

(c) Spread of cost function (11-OPTs)

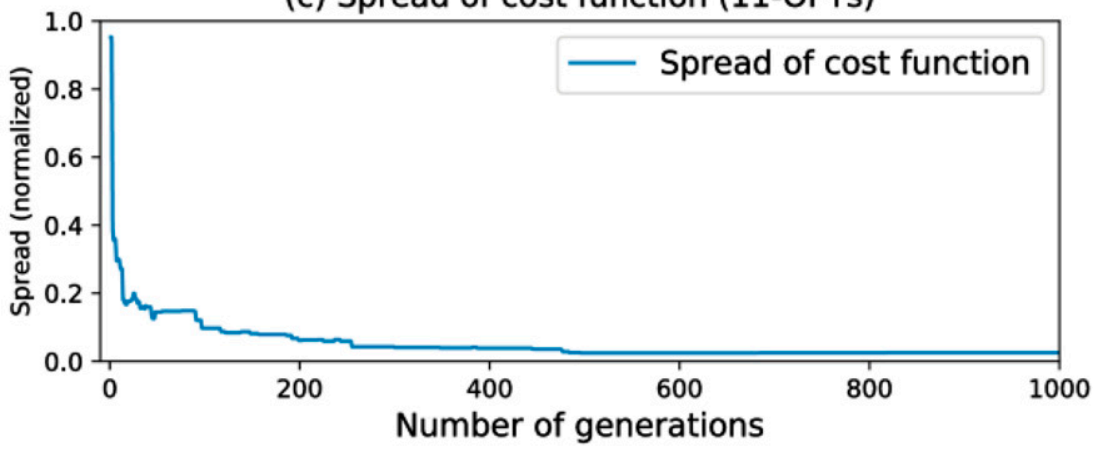

FIG. 2. (a) Evolution, (b) reduction rate, and (c) spread of the cost function from 11-OPTs. The dashed black line (=3.0) in (a) denotes the cost of CTRL. In (b), the mean reduction rate is given by the average of 11-OPTs applying a running mean over 100 generations. The spread of the cost in (a) and (c) is defined by the difference between the maximum and the minimum of the cost in 11-OPTs. The spread in (c) is normalized by the cost of CTRL.

covered areas between the simulation and the observation (viz., OSI SAF - in principle the observation uncertainty could be taken into account as well but is not done here). The IIEE in 11-OPTs exhibits a small spread particularly after 1997 , supporting the similarity of the spatial pattern of the sea ice cover in 11-OPTs.

The spatial patterns of the observed time mean sea ice concentration in winter and in summer are reasonably well captured by all the optimized simulations (Fig. 4). The spread of the mean ice concentration is generally smaller than $10 \%$ except in areas close to the ice edge in winter (Fig. 4, bottom row). Interannual variations of the spatial pattern of the extent are also well reproduced by 11-OPTs (Fig. 5). The ice edge in summer (the most difficult season to simulate) gets closer to the observation (see also Fig. 3c), with a spread comparable to the range of observational uncertainty (Ivanova et al. 2015). Note that the improvement of the extent and concentration occurs not only in the optimization window (1990-2012), but also outside of it (Figs. 3b,d, and Fig. 5 bottom row), 

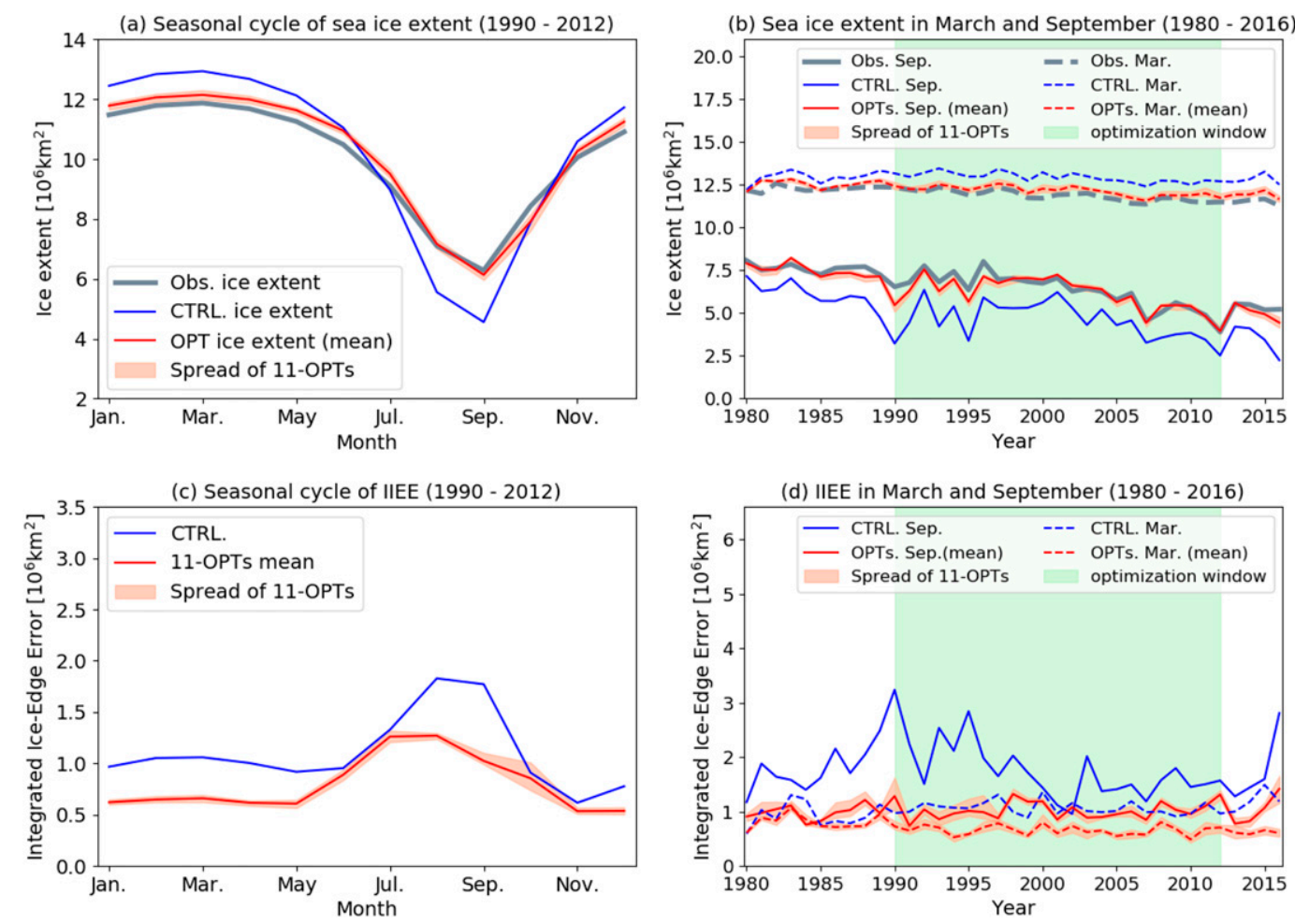

FIG. 3. (a) Seasonal cycle and (b) interannual variation of sea ice extent from observation (OSI-409; black), CTRL (blue), and mean of 11-OPTs (red). The sea ice extent is defined by $15 \%$ sea ice cover based on monthly mean data. (c) Seasonal cycle and (d) interannual variation of Integrated Ice-Edge Error (Goessling et al. 2016). The orange shade denotes the spread of 11-OPTs, which is defined by the difference between the maximum and minimum extent in 11-OPTs. In (b) and (d) the solid (dashed) lines denote the extent in September (March).

indicating the robustness of the simulations with the optimized parameters.

\section{2) SEA ICE THICKNESS}

The simulated thickness of 11-OPTs, as a whole, gets closer to the observed thickness with a sufficiently small spread (Fig. 6). The seasonal cycle of the pan-Arctic mean ice thickness gets closer to the observations from October to December, while it is overestimated from January to May (Fig. 6a). This overestimation stems from a bias toward thicker ice over the Siberian Shelf in winter in 11-OPTs (Fig. 7). The bias is also found in CTRL but for the areal mean compensated by a thin-bias over the area north of Greenland and the Canadian Archipelago (not shown). Since the overall spatial pattern of thickness in 11-OPTs gets closer to the observation, the local spatial bias is more emphasized in the mean thickness in winter. Note that a rootmean-squared thickness difference between model and observation averaged over the model domain (Fig. 6c), which takes account of spatial bias, does not show degradation of the simulated thickness in winter. A similar effect can be seen in the interannual variability of the mean winter and summer pan-Arctic thickness (Fig. 6b): the summer thickness gets closer to the observed decreasing trend, while the winter thickness is slightly degraded in 11-OPTs. The spread of the seasonal cycle as well as of the interannual variability in 11-OPTs is small compared to the seasonal cycle and the interannual variability. The spatial pattern of the thickness also exhibits sufficiently small spread (Fig. 7 bottom row). The largest spread found in the north of Greenland and the Canadian Archipelago, both in winter and in summer, is still sufficiently small compared to the thickness in that area $(\sim 10 \%$ of the thickness). In winter a large spread occurs also along the sea ice edge in the Greenland Sea as a consequence of the variability of the location of the sea ice edge in 11-OPTs.

\section{3) SEA ICE DRIFT}

The sea ice drift is generally improved by the optimizations (about 10\% reduction of drift costs). However, an assessment of the improvements is not as straightforward as for the other variables. Since we combined three different observational sea ice drift 
(a) Observation (annual)

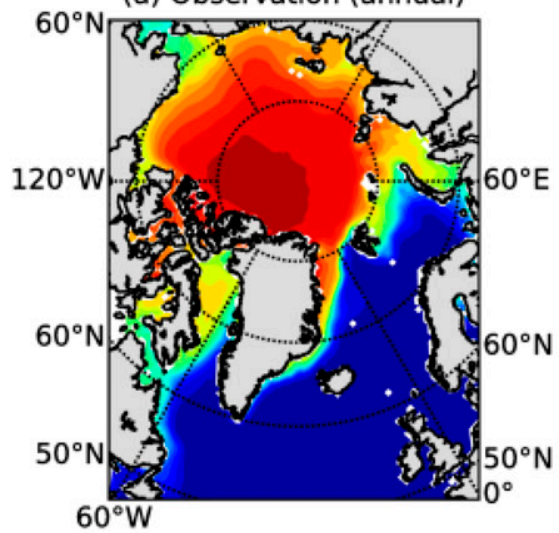

(d) 11-OPTs mean (annual)

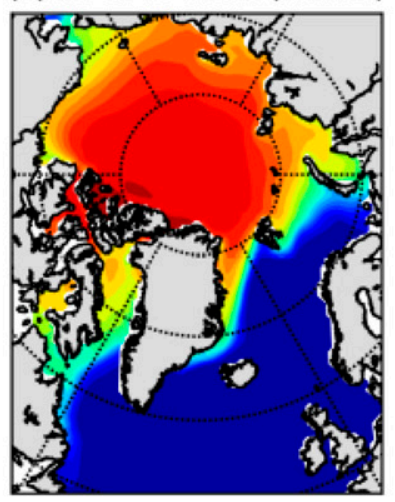

(g) Spread of 11-OPTs (annual)

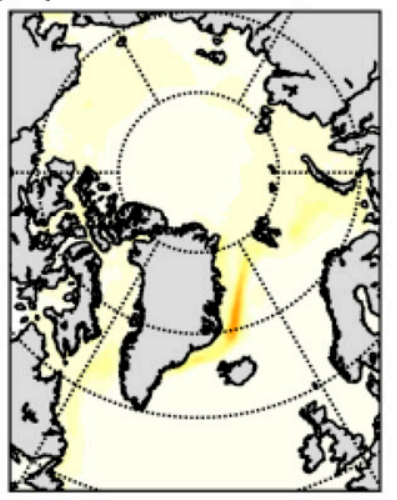

(b) Observation (winter)

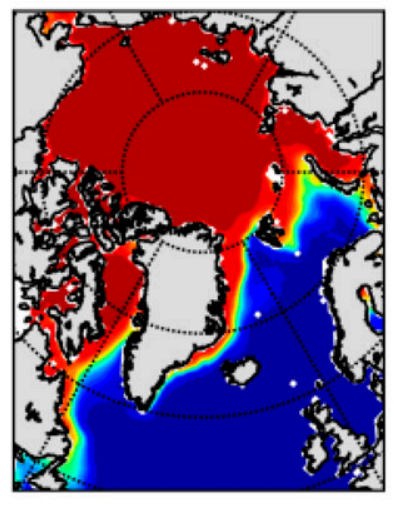

(e) 11-OPTs mean (winter)

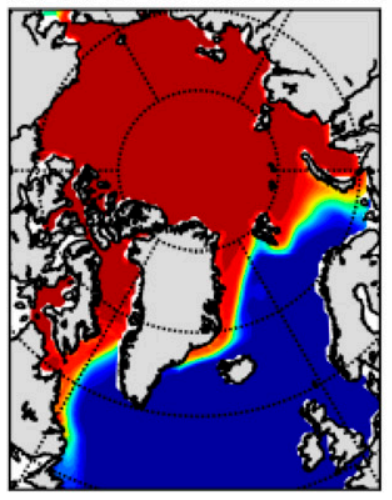

(h) Spread of 11-OPTs (winter)

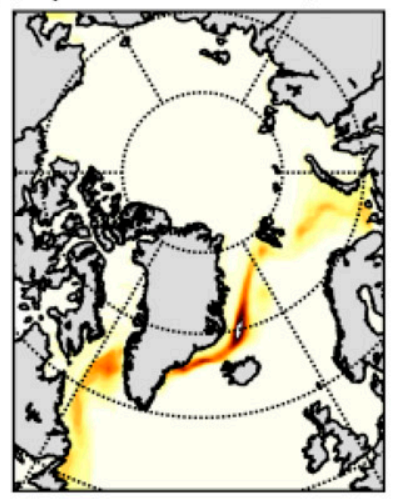

(c) Observation (summer)

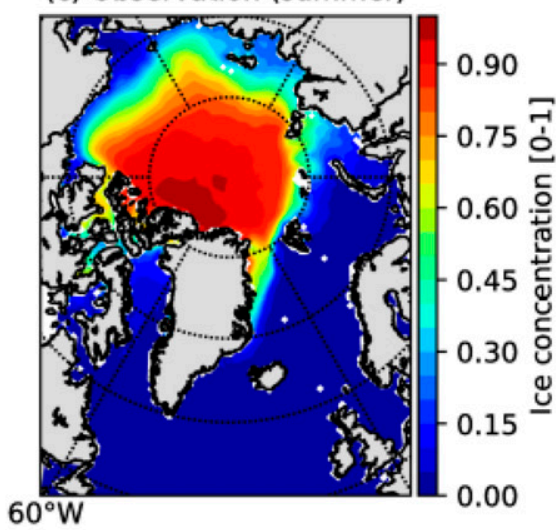

(f) 11-OPTs mean (summer)

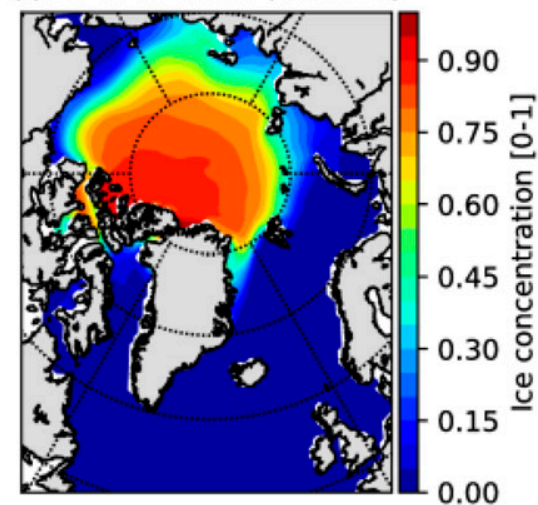

(i) Spread of 11-OPTs (summer)

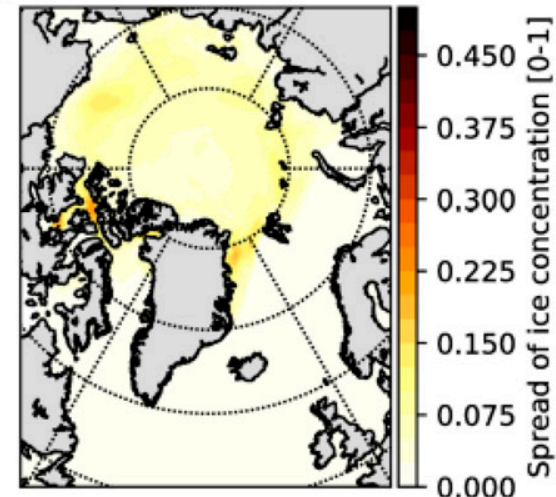

FIG. 4. Sea ice concentration from (a)-(c) observation, (d)-(f) the mean of 11-OPTs, and (g)-(i) the spread in 11-OPTs for 1990-2012. (left) Annual mean, (center) winter (February, March, April) mean, and (right) summer (August, September, October) mean. The spread of 11-OPTs is defined by the difference between the maximum and minimum mean ice concentration in 11-OPTs.

products to be able to cover the entire optimization window, errors and biases vary largely with time. As a result, an improvement of the drift occurs in a period covered by observations with a relatively small error, while a degradation occurs in a period covered by observations with larger errors. This is clearly seen in the temporal variations of the observed annual mean pan-Arctic drift speed (Fig. 8b). NSIDCv2, which is used for the cost evaluation form 1990-2002 and in the summers of 2011 and 2012, has the largest error among the three drift products (Sumata et al. 2015b) and a distinctive bias toward low-drift speeds (Szanyi et al. 2016). Since the cost function takes the observational error into account, the algorithm finds solutions matching the observations closely in $2002-10$ in which products with lower errors are used, while having a larger 


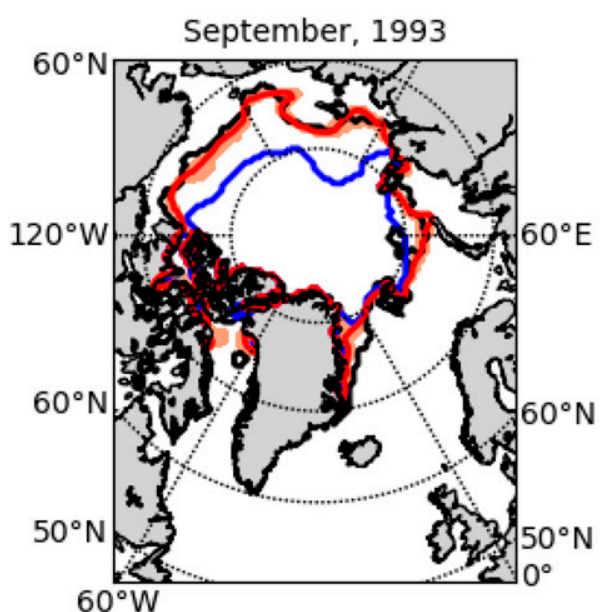

September, 2003

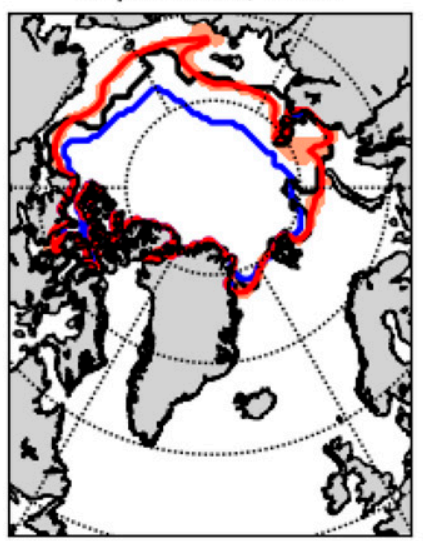

September, 2013

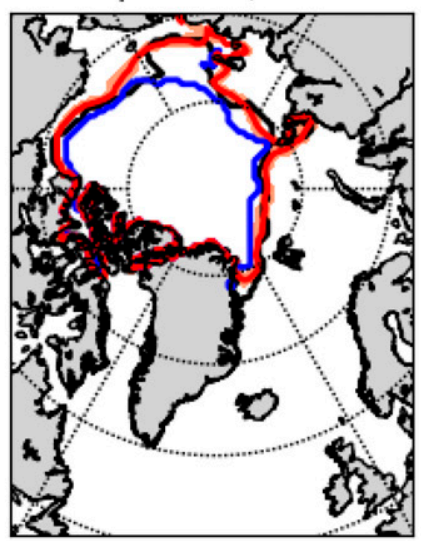

September, 1996

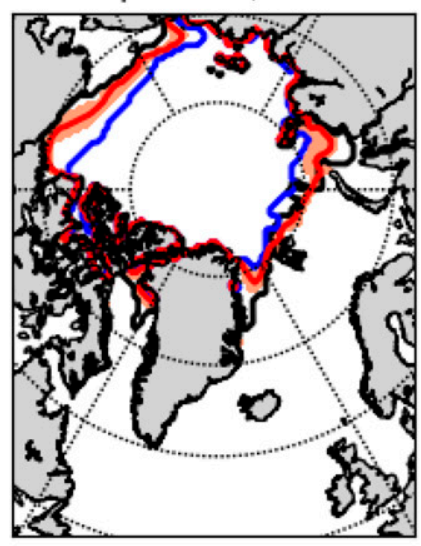

September, 2006

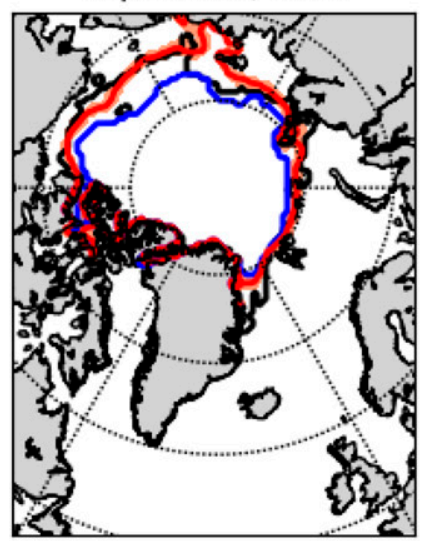

September, 2016

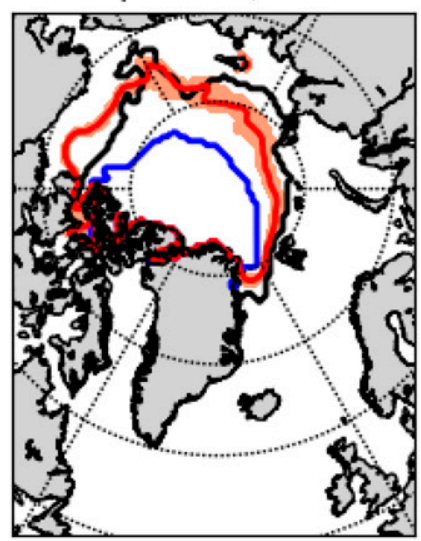

September, 1999

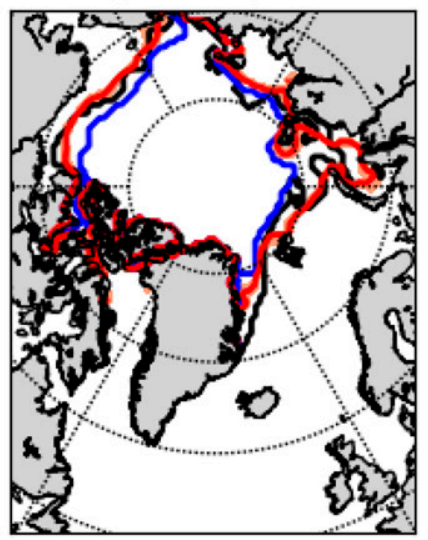

September, 2009

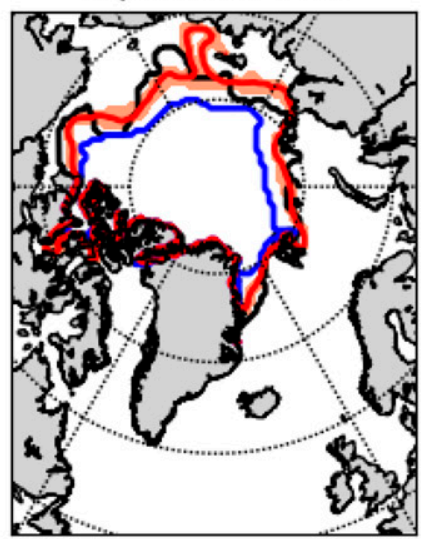

- Obs. ice extent

- CTRL ice extent

11-OPTs mean extent Spread of 11-OPTs

FIG. 5. Sea ice extent in September in the (top) 1990s, (middle) 2000s, and (bottom) 2010s of the observation, CTRL, and 11-OPTs (shown in every third years). The panels in the bottom row show the extent from the validation period (2013-16). The sea ice extent is defined as the area with larger than $15 \%$ concentration calculated from monthly mean data, and the spread of 11 -OPTs is defined as the difference of the maximum and minimum extent.

mismatch in 1990-2002 and in 2011 and 2012. This partial improvement is also evident in the seasonal cycle of the mean drift speed. As a result, the seasonal cycle calculated from the data from the entire optimization window gives a poorer result than CTRL (not shown). The period 2002-12, on the other hand, gives a better correspondence with observations in the winter months, although the summer drift speed is slightly 
(a) Seasonal cycle of sea ice volume (2000 - 2012)

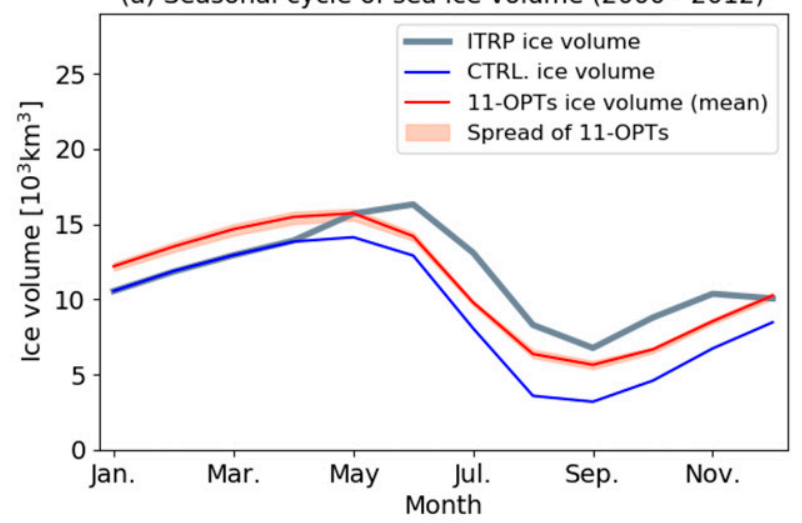

(c) Seasonal cycle of r.m.s. ice thickness error (2000 - 2012)

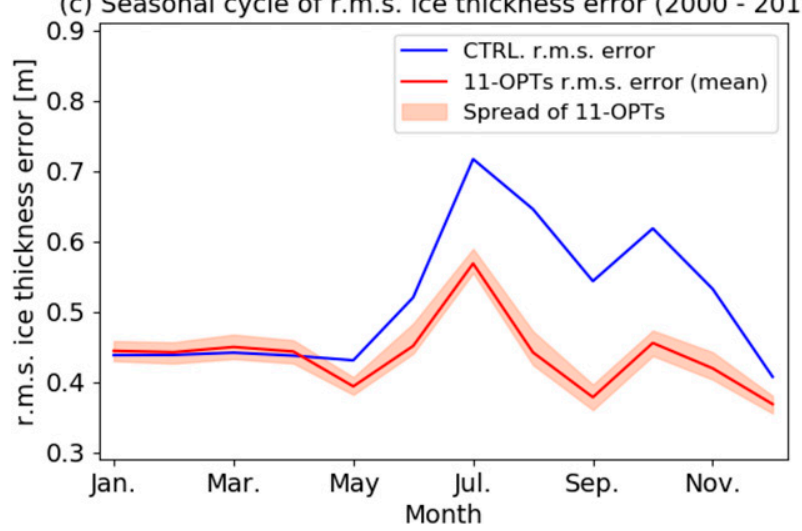

overestimated (Fig. 8a). The overestimation is partly due to the low-drift speed bias in the summer data from NSIDCv2 in 2011 and 2012. Unlike the other sea ice variables, the mean drift speed shows a spread comparable to the magnitude of the simulated interannual variation $\left(\sim 1 \mathrm{~cm} \mathrm{~s}^{-1}\right)$. It is, however, worth noting that regardless of the spread of the mean drift speed, 11-OPTs provides strikingly similar sea ice concentration, extent and thickness.

\section{b. Characteristics of the optimized parameters}

\section{1) Multiple optimal solutions}

Although we find convergence of the cost functions toward the same value of the minimum and a striking similarity of the spatial pattern and interannual variations of the sea ice fields, the corresponding optimal parameters for the 11 optimizations exhibit a large spread (Fig. 9). For example, the optimal value for the ice strength $\left(P^{*}\right)$ ranges from $1.73 \times 10^{4}$ to $4.01 \times$ $10^{4} \mathrm{~N} \mathrm{~m}^{-2}$; that for the wind drag coefficient $\left(C_{\text {dwin }}\right)$ ranges from $1.38 \times 10^{-3}$ to $2.48 \times 10^{-3}$, and that for the sea ice albedo $\left(\alpha_{i}\right)$ ranges from 0.665 to 0.923 . Although these are considered as key tuning parameters of sea ice models (e.g., Harder and Fischer 1999;

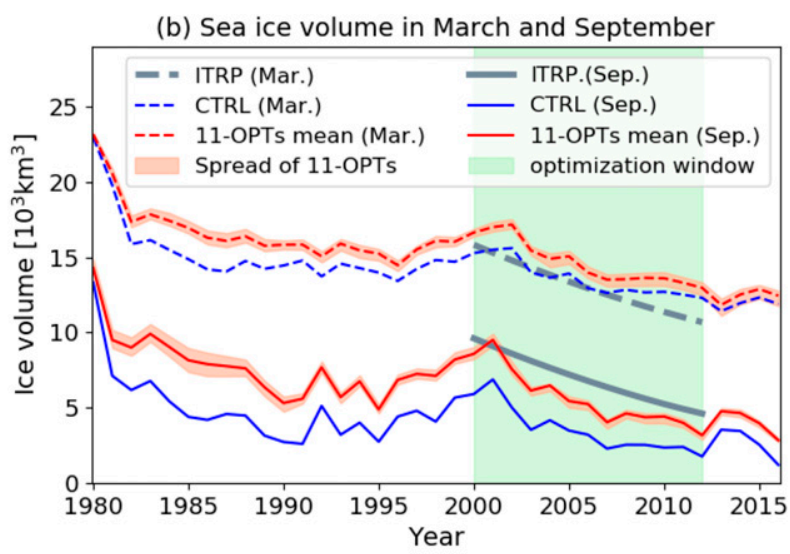

FIG. 6. (a) Seasonal cycle and (b) interannual variations of sea ice thickness from the Ice Thickness Regression Procedure (Lindsay and Schweiger 2015; black), CTRL (blue), and mean of 11-OPTs (red). (c) Root-mean-square ice thickness error averaged over the model domain. The orange shade denotes the spread in 11-OPTs. An area mask taken from the ICESat ice thickness product defining the inner Arctic (Kwok et al. 2009) is applied for the volume calculation.
Miller et al. 2006; Nguyen et al. 2011), the range of the optimized values is very large. Note that this result is not an indication for an insensitivity of the sea ice variables with respect to changes of these parameters, but it is a manifestation of the interdependence of these parameters [section $3 b(2)$ ]. Additional model runs with random combinations of parameter values taken from the spread ranges (depicted in Fig. 9) show that they do not necessarily give a cost close to the global minimum. In fact, they sometimes give a value of the cost function larger than in CTRL (not shown). It is worth noting that even though we use three types of sea ice observations covering the entire Arctic Ocean for about two decades, we cannot identify a unique set of optimal parameters. The existence of multiple solutions for the optimal parameters is possibly one of the reasons for the large spread of parameter values suggested in the literature.

\section{2) COVARIANCE OF THE OPTIMAL PARAMETER SETS}

As pointed out in previous studies, some of the model parameters have a counteracting effect on the sea ice variables (Harder and Fischer 1999; Hunke 2010). For instance, Harder and Fischer (1999) reported a 
(a) ITRP (annual)

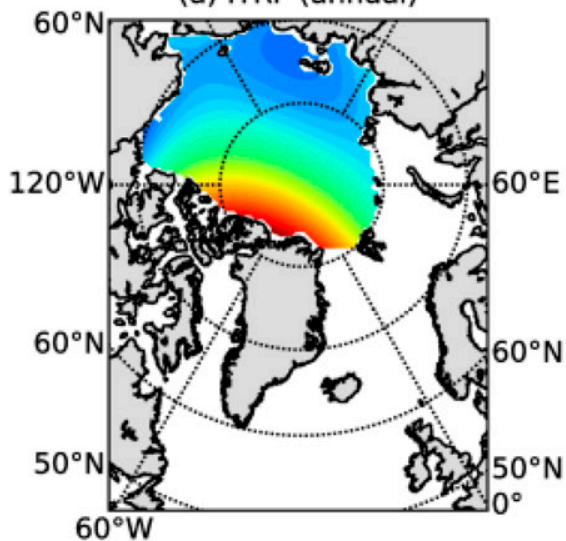

(d) 11-OPTs mean (annual)

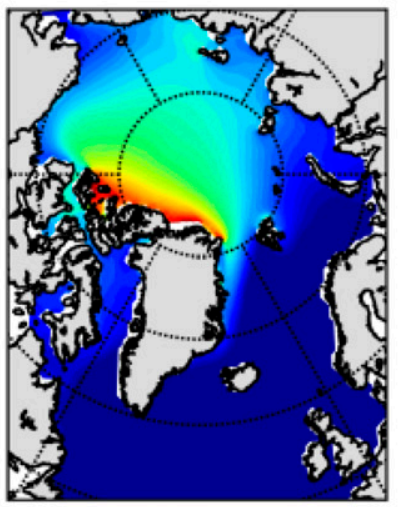

(g) Spread of 11-OPTs (annual)

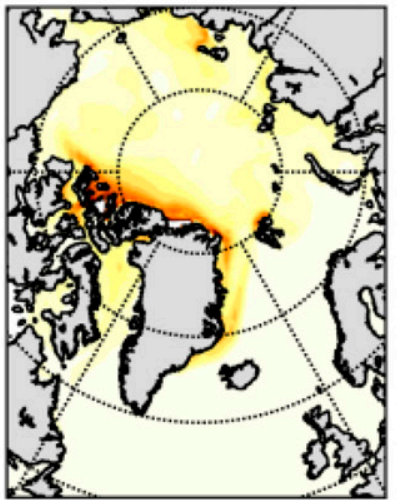

(b) ITRP (Apr.)

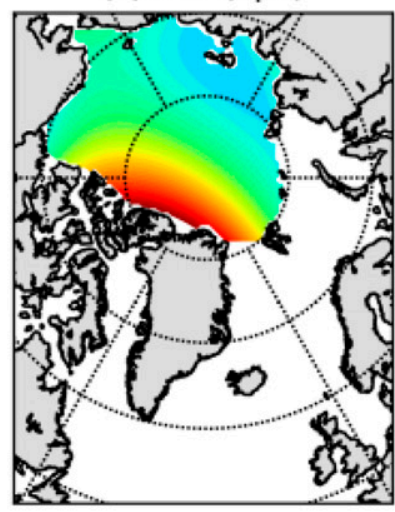

(e) 11-OPTs mean (Apr.)

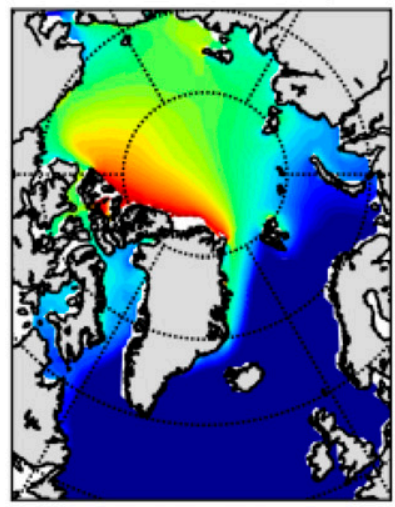

(h) Spread of 11-OPTs (Apr.)

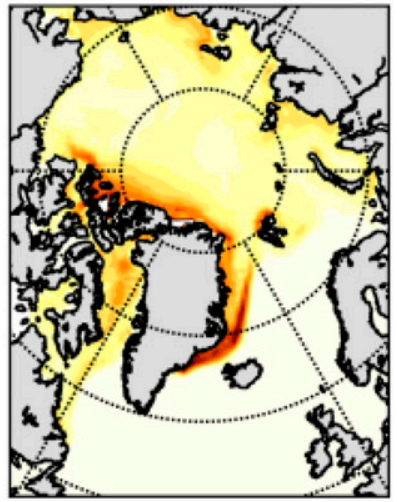

(c) ITRP (Oct.)

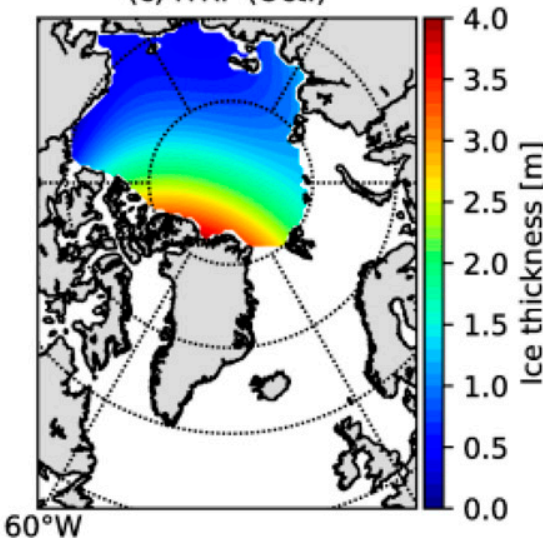

(f) 11-OPTs mean (Oct.)

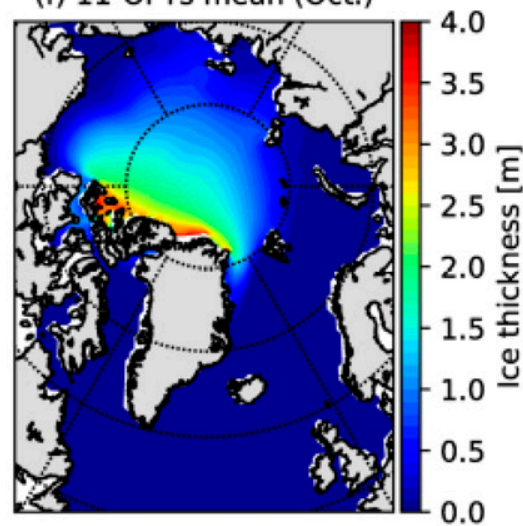

(i) Spread of 11-OPTs (Oct.)

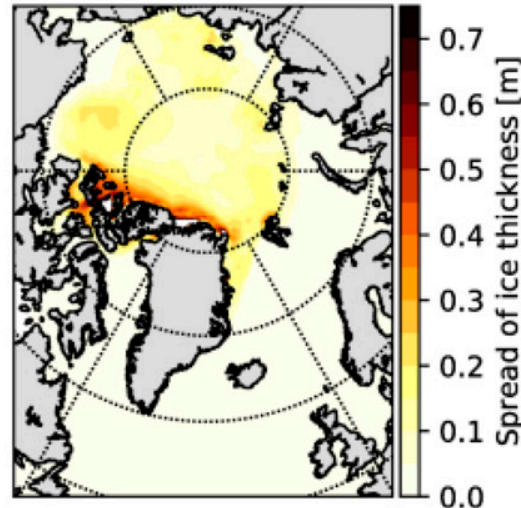

FIG. 7. Long-term mean (2000-12) of the sea ice thickness from (a)-(c) ITRP (Lindsay and Schweiger 2015), (d)-(f) 11-OPTs, and (g)-(i) the spread in 11-OPTs. (left) Annual mean, (center) April mean, and (right) October mean thickness.

counteracting effect of the wind and the water drag coefficients in their experimental setup. Figure 10 shows a scatterplot of all $P^{*}-C_{\mathrm{dwin}}$ combinations tested in the optimization experiments with costs close to the apparent global minimum. The (near) optimal values of $C_{\mathrm{dwin}}$ and $P^{*}$ are covariant: the larger $P^{*}$, the larger $C_{\text {dwin,. }}$ To quantitatively examine the relations between the optimal values of the 15 parameters, we define a sample set of (near) optimal parameter sets. The sample set is composed of parameter sets that give costs smaller than a threshold of 2.2, and are taken from populations composed of all parameter sets generated in 11-OPTs (i.e., from the parameter sets in 6 populations $\times 1000$ generations $\times 11$ optimizations). This procedure results in 209 parameter sets. Figure 11 summarizes the correlations between the optimal parameters for the 209 
(a) Seasonal cycle of ice drift speed (2002 - 2012)

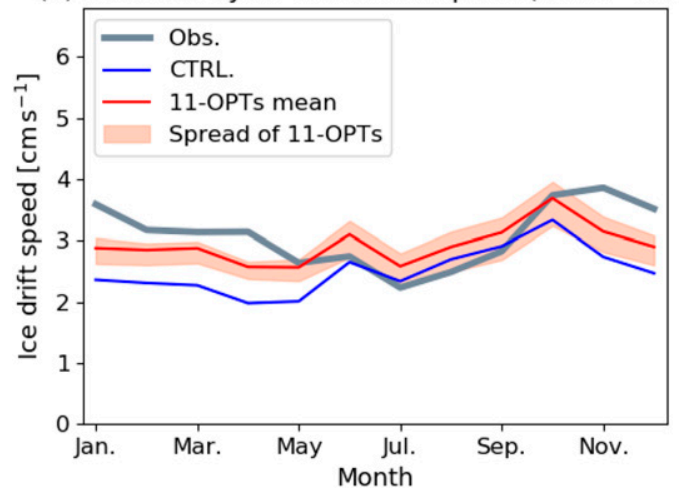

(b) Annual mean ice drift speed

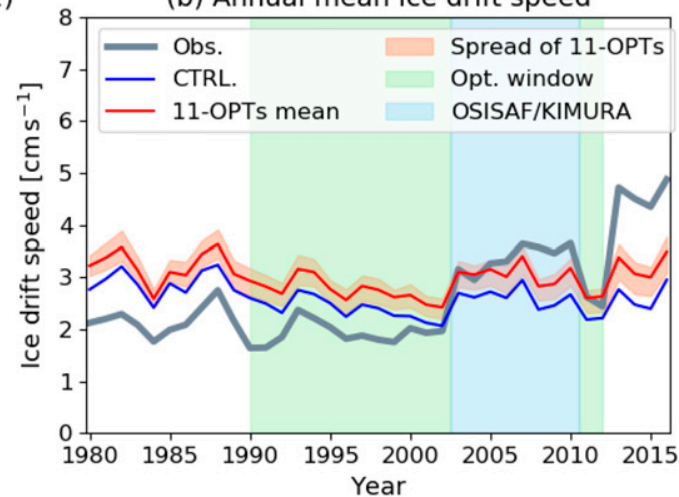

FIG. 8. (a) Mean seasonal cycle of the drift in 2002-12 and (b) interannual variations of the annual mean ice drift speed. The black, blue, and red lines denote the observations, CTRL, and the mean of 11-OPTS, respectively. The orange shade denotes the spread in 11-OPTs. The light green and sky blue shades in (b) show optimization window. For the light green period NSIDCv2 data are (partially) used to constrain the model parameters, while for the sky blue period OSISAF and/or KIMURA data are used. The area mask taken from observed ice drift field is applied to the modeled ice drift field for the comparison.

sets. We find high correlations or anticorrelations for some combinations of parameters. Since a parameter is sometimes correlated or anticorrelated with more than one other parameter, we find covariances of the optimal parameters that result in a contraction of the parameter space.

We also performed a principal component (PC) analysis of this dataset for further examination of the relation between variations of optimal parameter sets (i.e., to identify PCs that explain a large part of the variations of the optimal parameters and to distinguish parameter groups contributing to each
PCs). The first PC explains $37 \%$ of the variance of the (near) optimal parameters, and that the first three (six) PCs explain a total of $70 \%(90 \%)$ of the variance, indicating a reduction of the degrees of freedom and thus a reduction of the number of independent "tuning knobs" for the parameter tuning. Figure 12 shows the factor loading of each parameter on the first six PCs. As shown in this figure, the dynamic and thermodynamic model parameters are jointly contributing to the main PCs, for example, the first PC is composed of combined variations of dynamic $\left(P^{*}\right.$ and $\left.C_{\mathrm{dwin}}\right)$ and thermodynamic $\left(C_{\mathrm{lat}}, \alpha_{\mathrm{sm}}, \alpha_{i}\right.$, and $\left.\alpha_{\mathrm{im}}\right)$

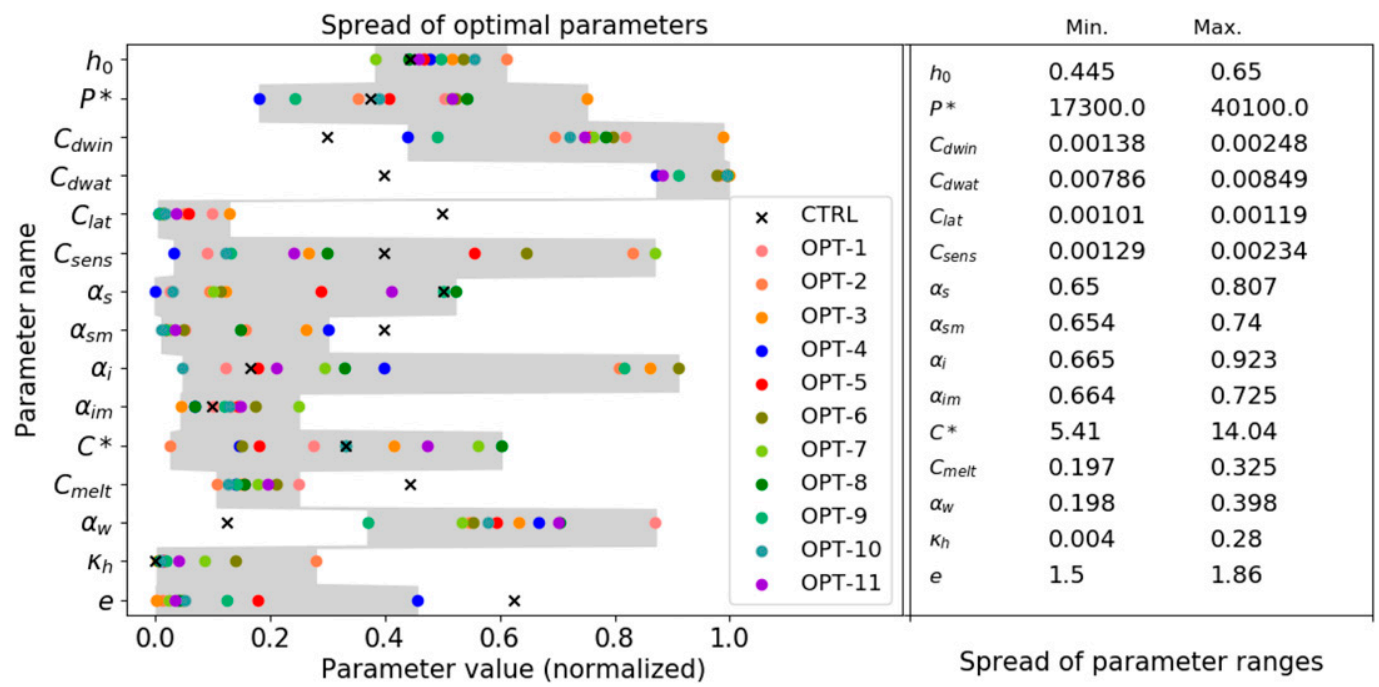

FIG. 9. Spread of optimal parameters. The search range of each parameter (see Table 1) is normalized such that 0 represents the lower bound and 1 the upper bound. The gray shade denotes the spread range of the optimal parameters. The minimum and maximum values of the optimal parameters are shown in the panel on the right hand side. The crosses denote the parameter values used in CTRL. 


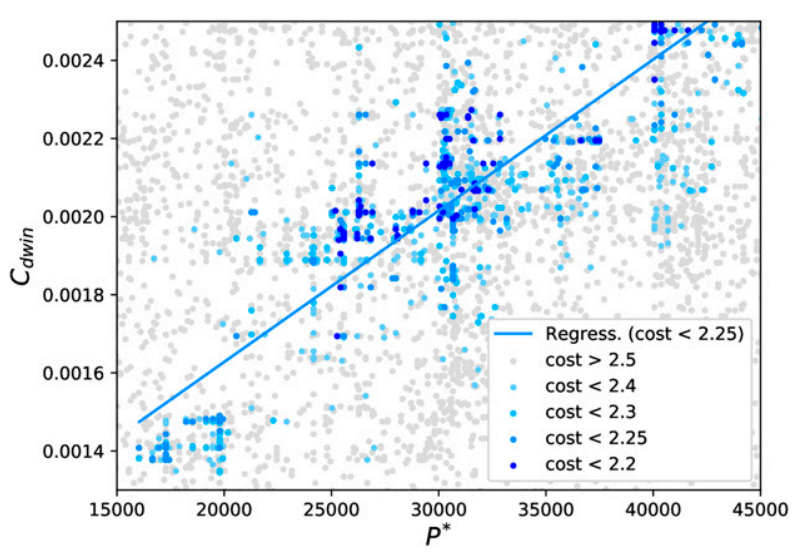

FIG. 10. Relation between $P^{*}$ and $C_{\mathrm{dwin}}$ obtained from the optimization experiments. The gray dots denote all $P^{*}-C_{\mathrm{dwin}}$ combinations tested in the optimization experiments, while the blue-colored dots denote combinations for which the costs are lower than thresholds defined in the legend. Note that one dot point does not necessarily correspond to a unique parameter set. It may represent more than two parameter sets in which the combination of $P^{*}$ and $C_{\text {dwin }}$ are the same, while other parameters are different.

model parameters (Fig. 12a), the second PC is also composed of combined variations of dynamic $(e)$ and thermodynamic $\left(h_{0}, C_{\text {sens }}\right.$, and $\left.\alpha_{s}\right)$ parameters (Fig. 12b). The robustness of this result is tested by a sample obtained from a slightly larger threshold of the costs (2.23), providing 440 sample parameter sets; the first three (six) PCs in this case explain 56\% (80\%) of the variance, and the factor loading of the first three
PCs are very similar to those calculated from the smaller sample size.

\section{Discussion}

\section{a. Implications of the parameter spread and covariances}

Four thermodynamic and three dynamic parameter values used in CTRL lie outside the spread ranges of the optimal parameters (Fig. 9). The thermodynamic parameters lying outside the spread are the latent heat transfer coefficient $\left(C_{\text {lat }}\right)$, albedo of melting snow $\left(\alpha_{\mathrm{sm}}\right)$, the area melting constant $\left(C_{\text {melt }}\right)$ and the albedo of seawater $\left(\alpha_{w}\right)$. Since CTRL significantly underestimates the sea ice extent in summer, the optimal values of these parameters cooperatively suppress the sea ice retreat in the melting season: $C_{\text {lat }}$ is reduced and thus prevents ice melt due to latent heat transfer, the area-melting constant $C_{\text {melt }}$ is reduced, too, which prevents the decrease of the ice-covered fraction when ice melt occurs, and the albedo of seawater $\alpha_{w}$ is enlarged, which reflects a larger amount of solar radiation and thus prevent ice melt in the marginal ice zones with only partial ice cover. The dynamic parameters lying outside the spread are the wind and water drag coefficient $\left(C_{\mathrm{dwin}}\right.$ and $\left.C_{\mathrm{dwat}}\right)$ and the eccentricity of the yield curve $(e)$. The distributions of these parameters indicate that a stronger dynamical coupling between atmosphere, sea ice and ocean (via larger $C_{\text {dwin }}$ and $C_{\text {dwat }}$ ) with a more shear-resistant sea ice (via a smaller

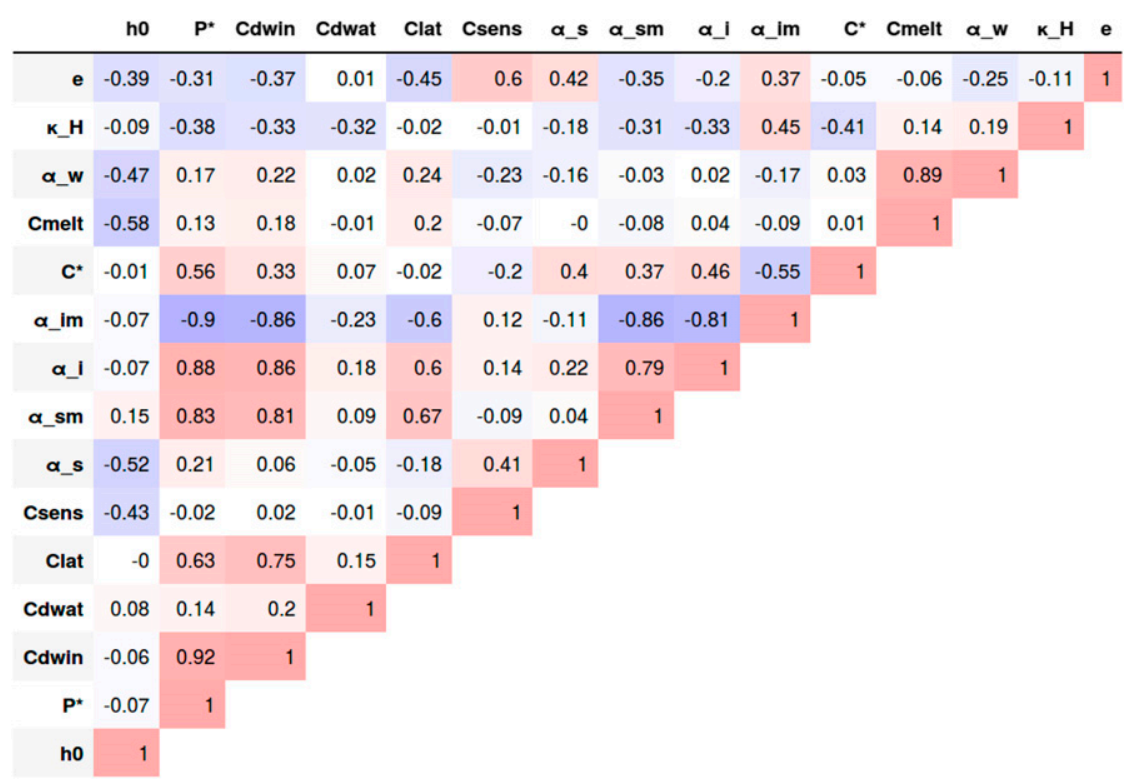

FIG. 11. Correlations between two parameters calculated from 209 sets of near-optimal parameters with costs lower than 2.2. The warm (cold) color shades indicate positive (negative) correlations. 
(a) PC 1, explained variance $=0.37$

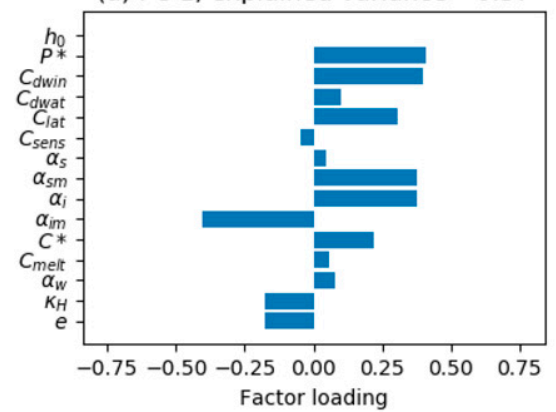

(c) PC 3, explained variance $=0.16$

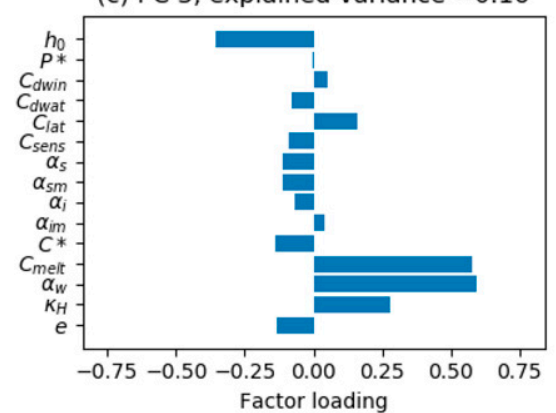

(e) PC 5, explained variance $=0.07$

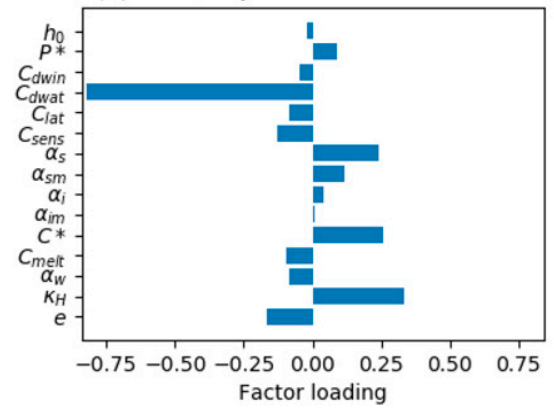

(b) PC 2, explained variance $=0.17$

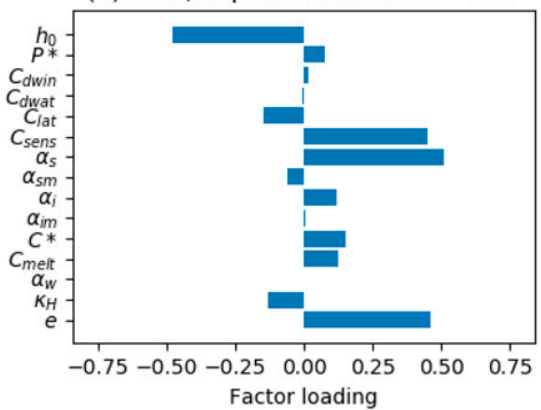

(d) PC 4, explained variance $=0.09$

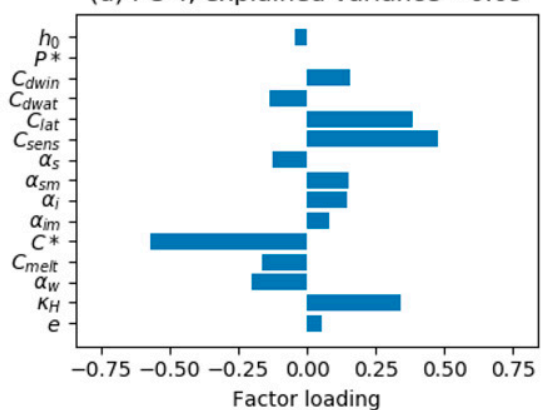

(f) PC 6, explained variance $=0.04$

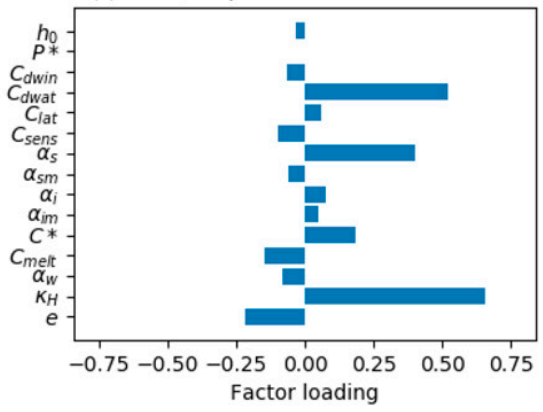

FIG. 12. Factor loading of the first six principal components (threshold of the cost function = 2.2 , number of sample parameter sets $=209$ ).

eccentricity of the yield curve, $e$ ) is necessary to arrive at a more realistic simulation of the sea ice fields with the current model set up.

The correlations between the optimized parameters (Fig. 11) guided us to the identification of counteracting or cooperatively acting processes in the modeled sea ice-ocean system. The high correlation between wind drag coefficient $\left(C_{\mathrm{dwin}}\right)$ and ice strength parameter $\left(P^{*}\right)$ implies that similar ice fields are achievable by combinations of stronger wind forcing with less compressible sea ice. The high anticorrelation between the albedo of melting snow $\left(\alpha_{\mathrm{sm}}\right)$ and melting ice $\left(\alpha_{\mathrm{im}}\right)$ implies that the total effect of the surface albedo evolution in the melting season can be achieved by compensating albedo values of melting snow and ice. The area-melting constant of sea ice $\left(C_{\text {melt }}\right)$ is strongly correlated with the albedo of seawater $\left(\alpha_{w}\right)$ : a large $C_{\text {melt }}$ enhances the reduction of the sea ice concentration during the melting process, it can be compensated by a larger $\alpha_{w}$, which decreases the ocean heat uptake by solar radiation and consequently the sea ice melt.

It is interesting that some parameters are well constrained by the optimization (e.g., $h_{0}, C_{\mathrm{dwat}}, C_{\mathrm{lat}}, \alpha_{\mathrm{im}}$, and $C_{\text {melt }}$ ), while others are not (e.g., $P^{*}, C^{*}, C_{\text {sens }}$, and $\alpha_{\text {ice }}$ ). The less constrained dynamic parameters (i.e., $P^{*}$ and $C^{*}$ ), are supposed to have spatial and temporal variations of the optimal values due to an accumulation of the local history of ice growth and deformation, which cannot be handled by the present parameterization of the model. We argue that in addition to the effect of counteracting or cooperatively acting processes discussed above, this might be an indication for the need to further refine the modeled physics, or at least the introduction of a stochastic parameterization approach for these parameters 
(a) CTRL

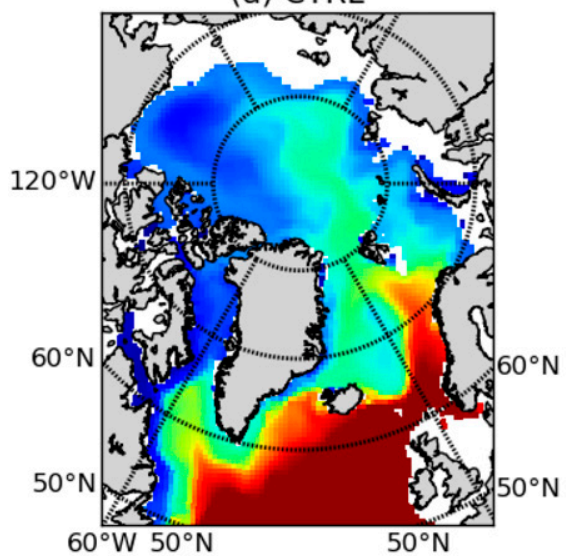

(d) Obs. 1990-2016

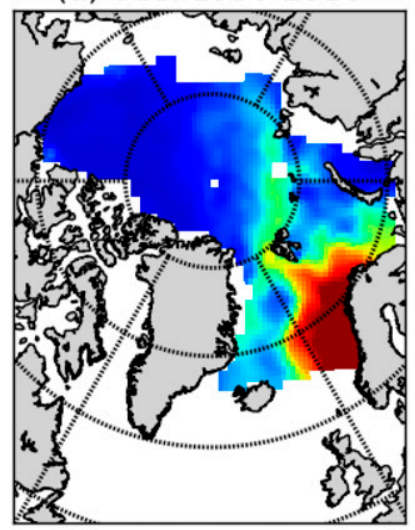

(b) 8-OPTs mean

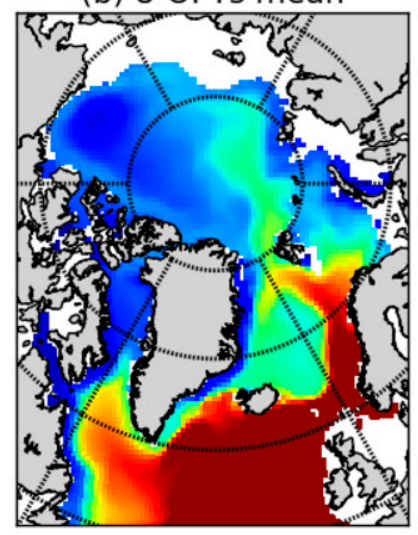

(e) $\mathrm{PHC} 3$

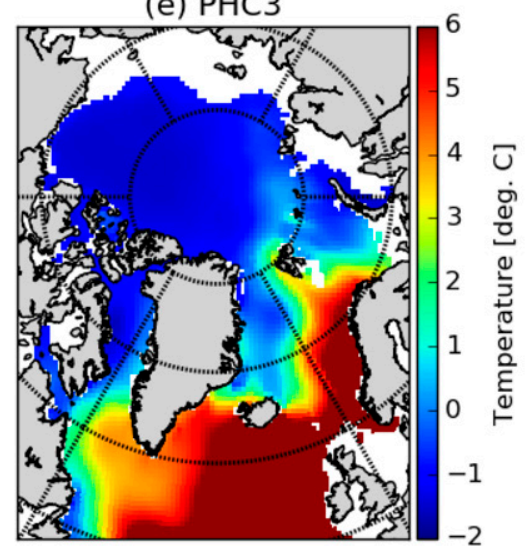

(c) Spread of 8-OPTs

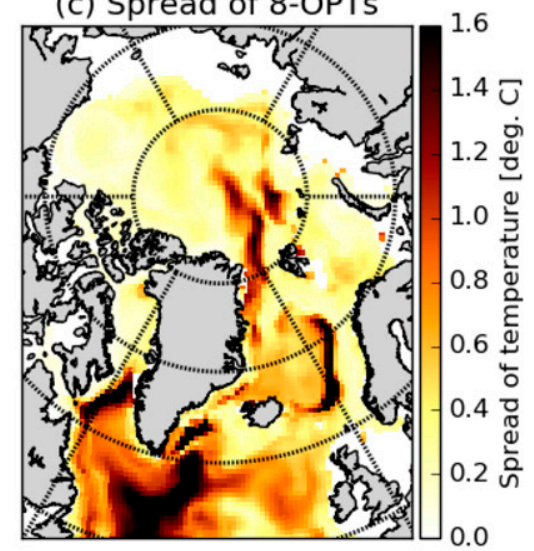

FIG. 13. Ocean temperature climatology in 138-m depth from (a) CTRL, (b) mean of 8-OPTs, (c) spread in 8-OPTs, (d) in situ observations (see below), and (e) PHC3 (Steele et al. 2001). For the mean in (b) and the spread in (c) calculations, three optimizations, which give the largest three $\mathrm{kH}$ (OPT-2, 6, and 7), are excluded to eliminate the direct effect of enhanced vertical diffusion. The climatologies in (a),(b) and the spread in 11-OPTs in (c) are calculated from the simulations in the period 1990-2016. (c) The observed field is calculated from observed data described in Sumata et al. (2018a) in the period 1990-2016 (see the appendix) while PHC3 is mainly based on observation in the 1980s and 1990s. The color bar for (a), (b), and (d) is shown in (e).

(Juricke et al. 2013; Brankart et al. 2015). The less constrained thermodynamic parameters (e.g., $C_{\text {sens }}$ and $\left.\alpha_{\text {ice }}\right)$ may represent processes that are subject to spatial and temporal variations as a consequence of the historical evolution of the sea ice surface properties. This might indicate the need for improvements of the parameterizations of thermodynamic processes.

We need to be aware that correlations or anticorrelations between optimal model parameters, or more generally, covariances of the optimal parameters, may strongly depend on the process formulation of the model, the setup of the modeling system (e.g., forced by atmospheric reanalysis or coupled to an atmospheric model), and the choice of the sea ice observations constraining the system. More elaborate process formulations (e.g., explicit representation of ice thickness categories, thermodynamic formulations explicitly describing the evolution of temperature profiles in sea ice and snow) naturally will lead to different parameter sensitivities (e.g., Urrego-Blanco et al. 2016) and covariances. Therefore it would be interesting to see how the covariances change when a sea ice model incorporating more processes (e.g., CICE; Craig et al. 2018) is optimized with the current method by using the same sea ice observations. This would show or at least give hints which of the found covariances are "robust." The current experiment employs a regional sea ice-ocean model forced by reanalysis data. Using a coupled atmospheric model instead, can be expected to considerably change the optimal values of the system, as well as the covariances between the optimal parameters due to the inclusion of feedbacks between the atmosphere, sea 
(a) CTRL

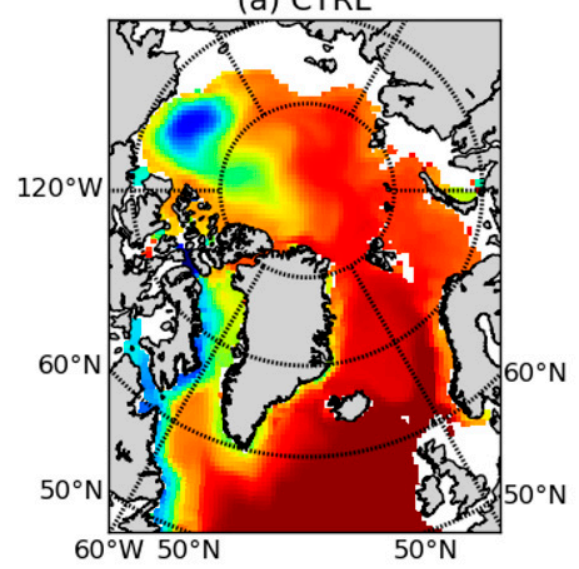

(d) Obs. 1990-2016

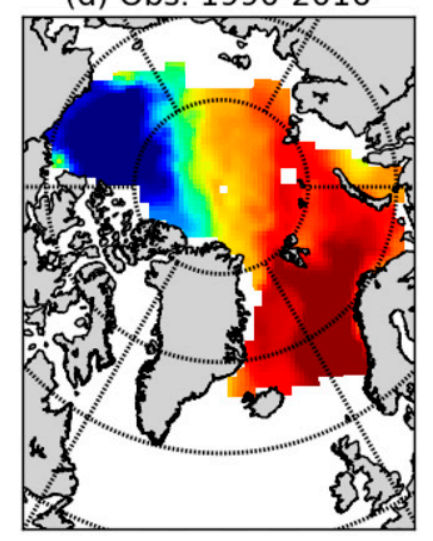

(b) 8-OPTs mean

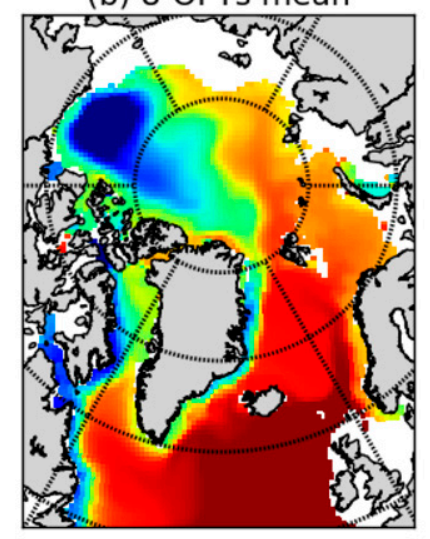

(e) $\mathrm{PHC3}$

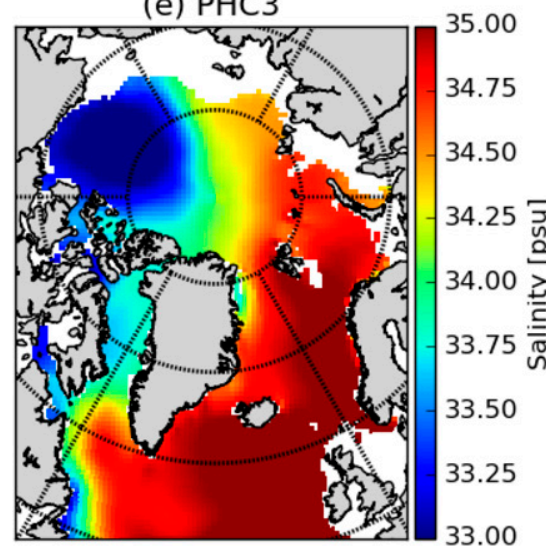

(c) Spread of 8-OPTs

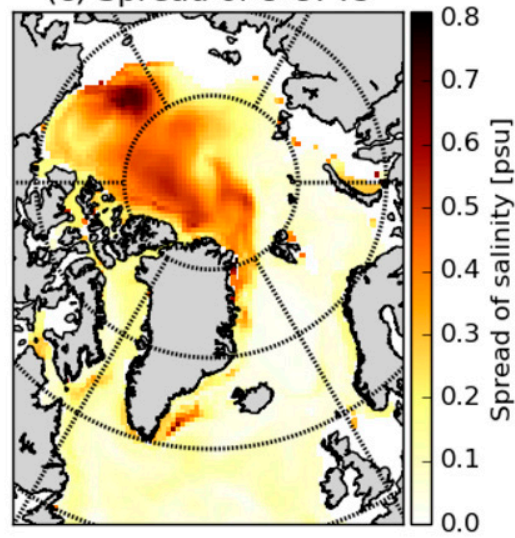

FIG. 14. As in Fig. 13, but for the ocean salinity in 138-m depth. ice and ocean. While a fully coupled atmosphere-sea ice-ocean system might also reduce the freedom in parameter space, an assessment of the model-observation misfit in a coupled system is hampered by the inherent internal variability of the system.

In summary, we argue that an examination of covariance (i.e., uncertainty of parameters constraining the system) using a sea ice model with a simple dynamic and thermodynamic formulation despite the limitations is a meaningful step toward understanding the complexity of the sea ice and snow system and its interaction with other components of the earth system. The covariance of the optimal parameters are a manifestation of the interactions between the dynamic and thermodynamic processes of the sea ice model, and are considered as a measure of the complexity of the system relative to the constraints provided by the available observational data.

\section{b. Potential utility of ocean observations}

The 11-OPTs give nearly the same minimum of the cost, and the associated sea ice fields are strikingly similar (section 3a). Without additional constraints we have no measure to decide which of the parameter sets better describes the coupled sea ice-ocean system. Further observed properties are necessary to better constrain the dynamic and thermodynamic sea ice processes. In fact we state that additional ocean properties (temperature and salinity) can be used as such additional constraints.

Figure 13 shows the spatial distribution of the simulated and observed ocean temperature and the spread in 8-OPTs at $138 \mathrm{~m}$ depth (representing approximately the depth of the upper Arctic halocline). We excluded the three optimizations with the largest values of $\kappa_{H}$ from 11-OPTs (OPT-2, 6, and 7). This allows us to distinguish the spread caused by the variation of the sea ice model parameters alone from the spread involving the direct effect of an increased $\kappa_{H}$. (The mean and spread calculated from 11-OPTs can be found in the online supplemental material.) While the mean temperature field of 8-OPTs shows better correspondence to the observations in the period 1990-2016 than CTRL 

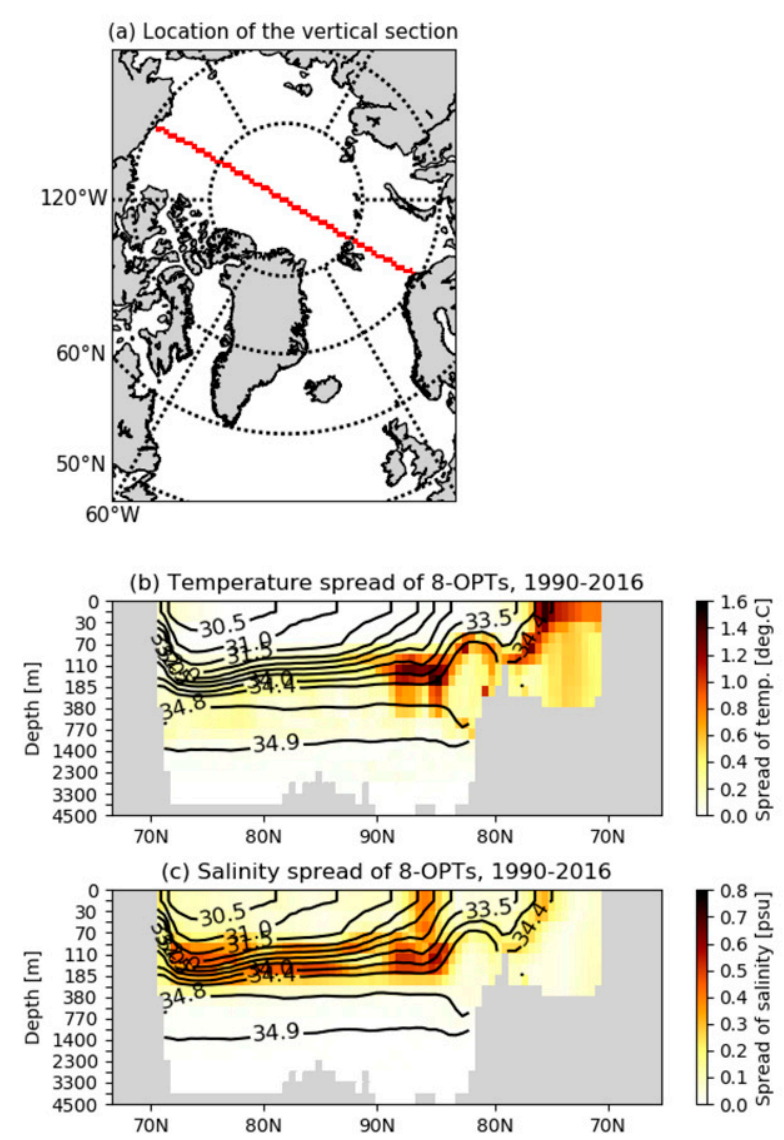
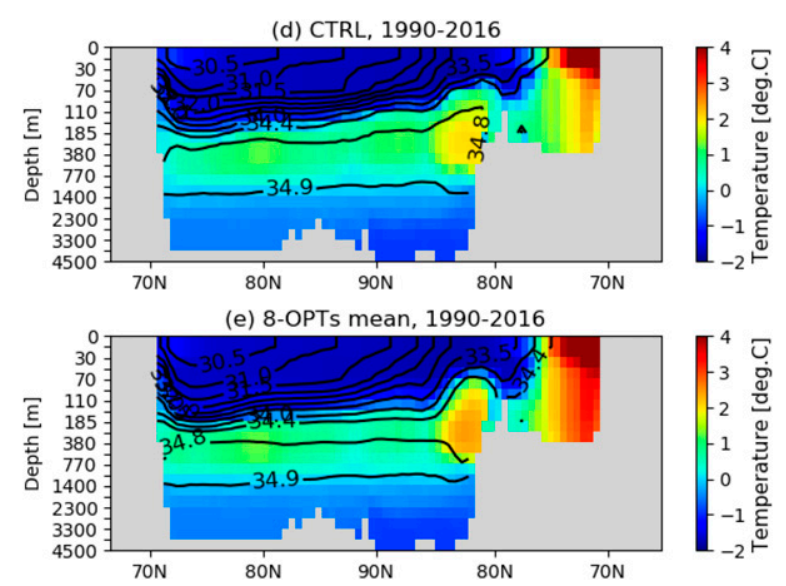

(f) Observation 1990-2016 mean

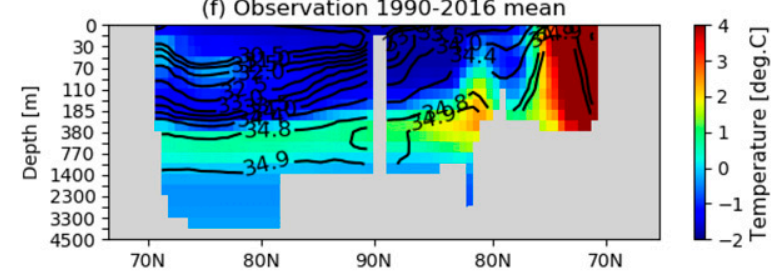

(g) PHC annual mean climatology

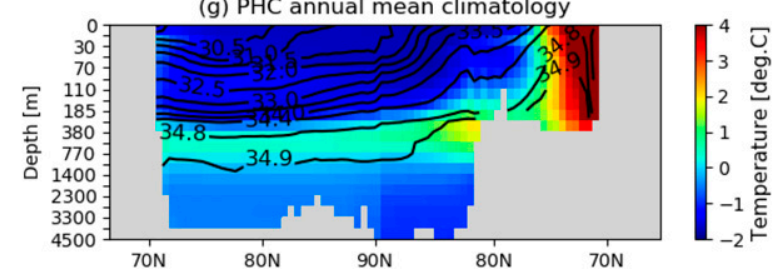

FIG. 15. Vertical sections of the ocean temperature and salinity and their spread along the $30^{\circ} \mathrm{E}$ and $150^{\circ} \mathrm{W}$ meridian. (left) (a) Location of the vertical section, (b) temperature spread of 8-OPTs, and (c) salinity spread of 8-OPTs. (right) Temperature and salinity on the section in (d) CTRL, (e) mean of 8-OPTs, (f) in situ observations (Sumata et al. 2018), and (g) PHC3 climatology. In (b),(c), the solid contour shows the salinity of the mean of 8-OPTs, while the color shows the spread. In the left panels $(\mathrm{d})-(\mathrm{g})$, the contours show the salinity while the colors denote temperature. Gray areas denote the topography in (a)-(g) and, in addition, missing data in (f). Note that the vertical coordinate is nonlinear.

(e.g., extension of warm Atlantic water along the Siberian shelf break), their spread shows that significant differences still exist between the eight optimized simulations (Fig. 13c). We find similar results for the salinity field (Fig. 14): the low saline pool in the Canada basin and the location of the salinity front between the Amerasian and the Eurasian basin in 8-OPTs is closer to the observations, while at the same time, the spread of salinity reaches 0.5 psu in the Amerasian basin. Interestingly, the largest spread does not occur just below the sea ice, but occurs at the lower part of the Arctic halocline for both the temperature and the salinity (Fig. 15). The large spread at the lower halocline implies that the different optimal parameter sets result in different dynamic states of the ocean.

Note that the significant spread of temperature found in the area south of Greenland (Fig. 13c) may be connected to the strong sensitivity of the deep water formation process to small perturbations (Kauker et al. 2005). Therefore, it is impossible to analyze if the spread is caused by the very small perturbation of $\kappa_{H}$ in 8-OPTs or by variations of ice model parameters. The spread of the temperature and salinity in 8-OPTs is distinctively larger than the uncertainty of the observed data, suggesting that ocean observations will provide additional valuable constraints on the coupled sea ice-ocean system and contribute to improve ocean properties. Therefore, including ocean observations will be an important next step.

\section{Conclusions}

We applied an automatic parameter optimization system to an Arctic sea ice-ocean model, and carried out a set of optimization experiments to investigate the optimality of the obtained ice field and uniqueness 
TABLE A1. List of additional observational data.

\begin{tabular}{ll}
\hline \hline Element of data compilation (alphabetical order) & \multicolumn{1}{c}{ Data source (URL or contact address) } \\
\hline Argo POPS & takashik@jamstec.go.jp, downloadable from Argo website \\
Healy (2015) Hydrographic Cruise & https://cchdo.ucsd.edu/cruise/33HQ20150809 \\
NABOS/CABOS mooring data, 2001-11, 2013-15 & http://nabos.iarc/uaf.edu/data/registered/main.php \\
NPEO JCAD buoys & http://ftp//northpoleftp.apl.washington.edu/NPEO_Data_Archive/NPEO_ \\
& JCAD_Buoys/ftp://northpoleftp.apl.washington.edu/NPEO_Data_Archive/ \\
NPEO_JCAD_Buoys/ & ftp://northpoleftp.apl.washington.edu/NPEO_Data_Archive/NPEO_Moorings/ \\
NPEO moorings & http://www.pangaea.de/ \\
Polar Stern cruise (PS51, PS85, PS86, PS87, PS93, & \\
PS94) & ftp://ftp.whoi.edu/whoinet/itpdata/ \\
ITP level 2 and level 3 data (update 2 Feb 2017) &
\end{tabular}

of the corresponding process parameters. 15 dynamic and thermodynamic model parameters were simultaneously optimized using three observed sea ice properties (concentration, thickness and drift) covering the entire Arctic Ocean for more than two decades. The system utilized a stochastic approach (genetic algorithm) to find the global minimum of the cost function.

All the optimizations successfully reduced the costs toward the same (global) minimum and provided sea ice fields much closer to the observations in comparison with the control simulation. From the small spread of the values of cost functions at the minimum and the striking similarity of the optimized sea ice fields of independent optimizations, we conclude that we have found the apparent global minimum of the cost function. Regardless of the striking similarity of the costs and sea ice fields, the corresponding parameter sets exhibit a large spread (i.e., multiple optimal solutions exist for the utilized Arctic sea ice model constrained by the used sea ice observations). The large spread of the optimal parameter sets is not an indication of insensitivity of ice fields to these parameters, but a manifestation of covariances of the optimal model parameters. A correlation analysis shows that the optimal values of many model parameters are correlated or anticorrelated. A principal component analysis reveals that a contraction of the parameter space occurs; the first three (six) principal components explain $70 \%$ (90\%) of the total variance of the optimal parameters, indicating that we can tune the model with a fewer number of tuning knobs by using the leading principal components and variate coefficients.

It is worth mentioning that even using three observed sea ice properties covering more than two decades, we cannot define a unique optimal parameter set for Arctic sea ice simulations which employs a simple physics (VP-rheology with a zero-layer thermodynamic formulation). Further constraints from observations are necessary to unambiguously describe the dynamic and thermodynamic processes in the coupled sea ice-ocean system. Analyses of the simulated ocean fields suggest a potential of ocean observations for that purpose; the large spread found in the simulated ocean fields indicates their relation to the parameters governing the sea ice dynamics and thermodynamics. A recently compiled Arctic hydrographic database (Behrendt et al. 2018) and associated decorrelation-scale estimates (Sumata et al. 2018a) can be used to provide further constraints on the sea ice-ocean modeling system for the Arctic Ocean.

Acknowledgments. We sincerely appreciate three referees (Dr. Andrew Robert and two anonymous reviewers) for their thorough reviews and constructive suggestions, which significantly contributed to improve the manuscript. Funding by the Helmholtz Climate Initiative REKLIM (Regional Climate Change), a joint research project of the Helmholtz Association of German research centers (HGF) is gratefully acknowledged. We also would like to express our appreciation toward the German Federal Ministry of Education and Research (BMBF) for the support of the project "RACE II-Regional Atlantic Circulation and Global Change" (03F0729E). This work was partly supported by European Commission as part of FP7 Project Ice, Climate, and Economics-Arctic Research on Change (ICE-ARC, Project 603887). We appreciate David L. Carroll for providing the FORTRAN genetic algorithm driver, which was used as the basis of the mGA optimization system. We also appreciate observational efforts to obtain the in situ hydrographic data listed in the table in the appendix. The link to the data source is shown in the table.

\section{APPENDIX}

\section{Arctic Ocean Hydrography for 1990-2016}

A hydrographic dataset of the Arctic Ocean is compiled for model validations and planned future data 

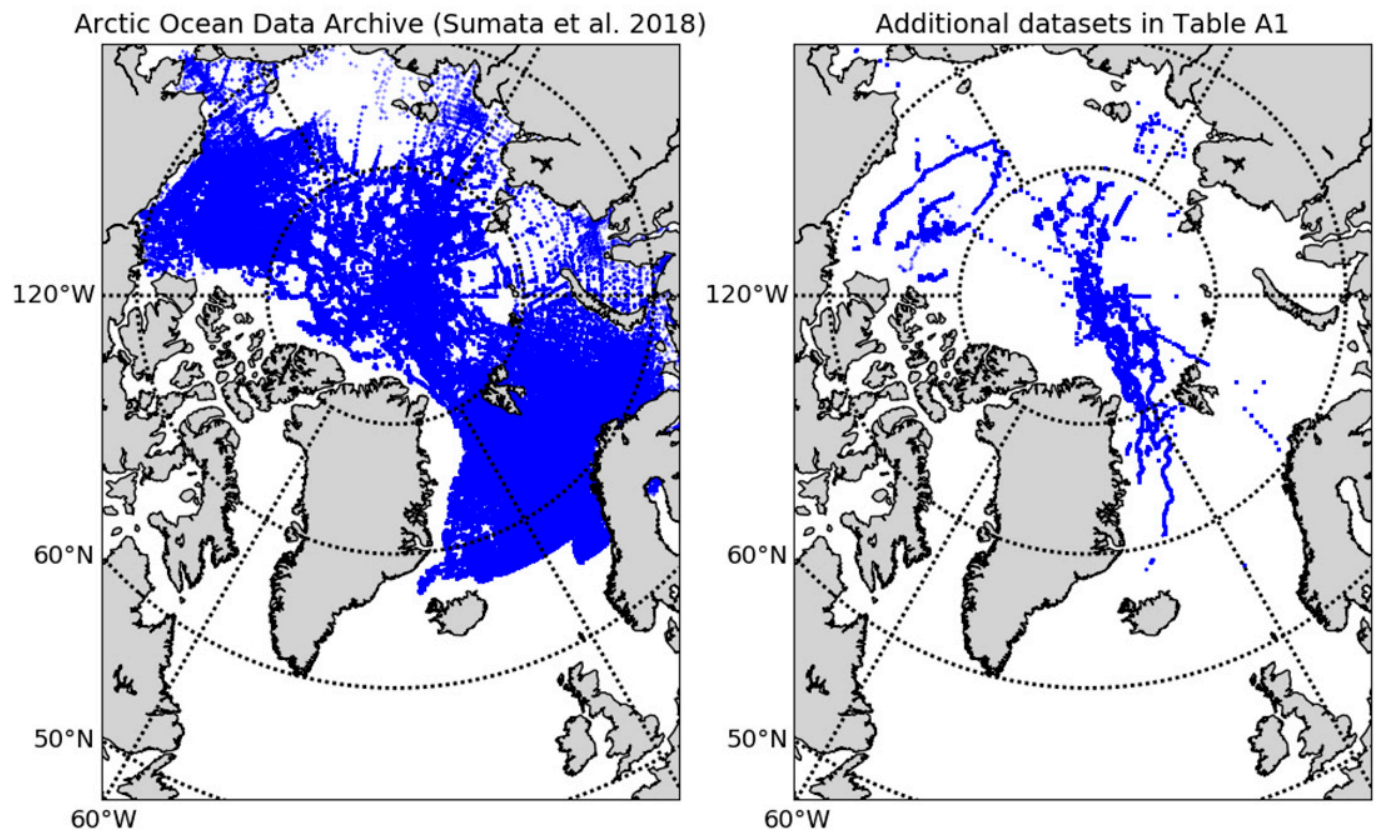

FIG. A1. Distribution of ocean in situ measurement data from (left) Sumata et al. (2018) and (right) additional datasets listed in Table A1.

assimilations. The dataset is composed of hydrographic data archive described in Sumata et al. (2018a) and some additional datasets (Table A1). The dataset contains in situ temperature and salinity measurements from various observational platforms (e.g., research vessels, moorings, Ice Tethered Platforms, Argo floats) covering the Arctic Ocean from 1980 to 2016 (Fig. A1). We applied a quality control (QC) procedure described in Sumata et al. (2018a) to the merged dataset. The QC procedure composed of 1) a basic quality check (topographic test using IBCAO/ETOPO5, valid range test and vertical stability test), 2) duplication check, and 3) statistical screening (a grid-based screening and area-based screening). The quality controlled dataset is then used to construct gridded temperature and salinity fields to facilitate use of model validation. The gridding procedure is composed of following steps: 1) define four seasons (winter: January-March, spring: April-Jun, summer: July-September, autumn: October-December); 2) calculate seasonal mean climatology of temperature and salinity by the average of data contained in each $110 \mathrm{~km} \times 110 \mathrm{~km}$ grid cell; 3 ) if the number of available data at a certain grid cell is fewer than three, define the climatology for the cell by the average of neighboring eight grid cell (spatial interpolation); 4) if the climatological value is not defined after the third step, define the climatology for the cell by the average of neighboring seasons; 5) calculate annual mean climatology by averaging four seasons; and finally 6) a 9-point smoothing is applied.

\section{REFERENCES}

Athias, V., P. Mazzega, and C. Jeandel, 2000: Selecting a global optimization method to estimate the oceanic particle cycling rate constants. J. Mar. Res., 58, 675-707, https://doi.org/ $10.1357 / 002224000321358855$.

Behrendt, A., H. Sumata, B. Rabe, and U. Schauer, 2018: UDASH-Unified Database for Arctic and Subarctic Hydrography. Earth Syst. Sci. Data, 10,1119-1138, https:// doi.org/10.5194/essd-10-1119-2018.

Blayo, É., M. Bocquet, E. Cosme, and L. F. Cugliandolo, 2015: Advanced Data Assimilation for Geosciences. Oxford University Press, 584 pp.

Bouchat, A., and B. Tremblay, 2017: Using sea-ice deformation fields to constrain the mechanical strength parameters of geophysical sea ice. J. Geophys. Res. Oceans, 122, 5802-5825, https://doi.org/10.1002/2017JC013020.

Brankart, J.-M., G. Candille, F. Garnier, C. Calone, A. Melet, P.-A. Bouttier, P. Brasseur, and J. Verron, 2015: A generic approach to explicit simulation of uncertainty in the NEMO ocean model. Geosci. Model Dev., 8, 1285-1297, https://doi.org/ 10.5194/gmd-8-1285-2015.

Castro-Morales, K., F. Kauker, M. Losch, S. Hendricks, K. Riemann-Campe, and R. Gerdes, 2014: Sensitivity of simulated Arctic sea ice to realistic ice thickness distributions and snow parameterizations. J. Geophys. Res. Oceans, 119, 559571, https://doi.org/10.1002/2013JC009342.

Chapman, W. L., W. J. Welch, K. P. Bowman, J. Sacks, and J. E. Walsh, 1994: Arctic sea ice variability: Model sensitivities 
and a multidecadal simulation. J. Geophys. Res., 99, 919-935, https://doi.org/10.1029/93JC02564.

Coello, C. A. C., and G. T. Pulido, 2001: A Micro-Genetic Algorithm for multiobjective Optimization. EMO 2001, E. Zitzler et al., Eds., LNCS 1993, Springer-Verlag, 126-140.

Craig, T., and Coauthors, 2018: CICE-Consortium/CICE: CICE version 6.0.0. Zenodo, accessed 13 March 2019, https://doi.org/ 10.5281/zenodo.1900639.

Docquier, D., F. Massonnet, A. Barthélemy, N. F. Tandon, O. Lecomte, and T. Fichefet, 2017: Relationships between Arctic sea ice drift and strength modelled by NEMOLIM3.6. Cryosphere, 11, 2829-2846, https://doi.org/10.5194/ tc-11-2829-2017.

Dumont, D., Y. Gratton, and T. E. Arbetter, 2009: Modeling the dynamics of the North Water polynya ice bridge. J. Phys. Oceanogr., 39, 1448-1461, https://doi.org/10.1175/ 2008JPO3965.1.

Eastwood, S., M. Jenssen, T. Lavergne, A. M. Sørensen, and R. Tonboe, 2017: Global sea ice concentration climate data record: Product user manual. Product OSI-450 and OSI-430-b, EUMETSAT Network of Satellite Application Facilities, 33 pp., http://osisaf.met.no/docs/osisaf_cdop3_ss2_pum_sea-ice-concclimate-data-record_v2p0.pdf.

Eisenman, I., N. Untersteiner, and J. S. Wettlaufer, 2007: On the reliability of simulated Arctic sea ice in global climate models. Geophys. Res. Lett., 34, L10501, https://doi.org/ 10.1029/2007GL029914.

Flato, G. M., and W. D. Hibler, 1991: An initial numerical investigation of the extent of sea-ice ridging. Ann. Glaciol., 15, 31-36, https://doi.org/10.1017/S0260305500009514.

Fowler, C., W. Emery, and M. Tschudi, 2013: Polar pathfinder daily $25 \mathrm{~km}$ EASE-Grid sea ice motion vectors, version 2 (daily and mean gridded field). NASA DAAC, National Snow and Ice Data Center, Boulder, CO, accessed 23 February 2016, https://doi.org/10.5067/LHAKY495NL2T.

Gerdes, R., M. J. Karcher, F. Kauker, and U. Schauer, 2003: Causes and development of repeated Arctic Ocean warming events. Geophys. Res. Lett., 30, 1980, https://doi.org/10.1029/ 2003GL018080.

Goessling, H. F., S. Tietsche, J. J. Day, E. Hawkins, and T. Jung, 2016: Predictability of the Arctic sea ice edge. Geophys. Res. Lett., 43, 1642-1650, https://doi.org/10.1002/2015GL067232.

Goldberg, D. E., 1989: Genetic Algorithms in Search, Optimization and Machine Learning. Addison-Wesley, $432 \mathrm{pp}$.

Harder, M., 1996: Dynamik, Rauhigkeit und Alter des Meereises in der Arktis (Dynamics, roughness, and age of Arctic sea ice). Ph.D thesis, Universität Bremen, Bremen, Germany, 129 pp. , and H. Fischer, 1999: Sea ice dynamics in the Weddell Sea simulated with an optimized model. J. Geophys. Res., 104, 11 151-11 162, https://doi.org/10.1029/1999JC900047.

Hibler, W. D., 1979: A dynamic thermodynamic sea ice model. J. Phys. Oceanogr., 9, 815-846, https://doi.org/10.1175/ 1520-0485(1979)009<0815:ADTSIM > 2.0.CO;2.

— Oceanogr., 17, 987-1015, https://doi.org/10.1175/1520-0485(1987) 017<0987:ADIM > 2.0.CO;2.

Holland, J. H., 1975: Adaption in Natural and Artificial Systems: An Introductory Analysis with Applications to Biology, Control, and Artificial Intelligence. University of Michigan Press, 183 pp.

Holland, D. M., L. A. Mysak, D. K. Manak, and J. Oberhuber, 1993: Sensitivity study of a dynamic thermodynamic sea ice model. J. Geophys. Res., 98, 2561-2586, https://doi.org/ 10.1029/92JC02015.
Hunke, E. C., 2010: Thickness sensitivities in the CICE sea ice model. Ocean Modell., 34, 137-149, https://doi.org/10.1016/ j.ocemod.2010.05.004.

— W. H. Lipscomb, and A. K. Turner, 2010: Sea-ice models for climate study: Retrospective and new directions. J. Glaciol., 56, 1162-1172, https://doi.org/10.3189/002214311796406095.

Ivanova, N., and Coauthors, 2015: Inter-comparison and evaluation of sea ice algorithms: Towards further identification of challenges and optimal approach using passive microwave observations. Cryosphere, 9, 1797-1817, https://doi.org/ 10.5194/tc-9-1797-2015.

Juricke, S., P. Lemke, R. Timmermann, and T. Rackow, 2013: Effects of stochastic ice strength perturbation on Arctic finite element sea ice modeling. J. Climate, 26, 3785-3802, https:// doi.org/10.1175/JCLI-D-12-00388.1.

Kalnay, E., and Coauthors, 1996: The NCEP/NCAR 40-Year Reanalysis Project. Bull. Amer. Meteor. Soc., 77, 437-471, https://doi.org/10.1175/1520-0477(1996)077<0437:TNYRP> 2.0.CO;2.

Karcher, M., F. Kauker, R. Gerdes, E. Hunke, and J. Zhang, 2007: On the dynamics of Atlantic Water circulation in the Arctic Ocean. J. Geophys. Res., 112, C04S02, https://doi.org/10.1029/ 2006JC003630.

— J. N. Smith, F. Kauker, R. Gerdes, and W. M. Smethie Jr., 2012: Recent changes in Arctic Ocean circulation revealed by iodine-129 observations and modeling. J. Geophys. Res., 117, C08007, https://doi.org/10.1029/2011JC007513.

Kauker, F., R. Gerdes, M. Karcher, C. Köberle, and J. L. Lieser, 2003: Variability of Arctic and North Atlantic sea ice: A combined analysis of model results and observations from 1978 to 2001. J. Geophys. Res., 108, 3182, https://doi.org/ 10.1029/2002JC001573.

,,--- _ and -2005 : Impact of North Atlantic Current changes on the Nordic Seas and the Arctic Ocean. J. Geophys. Res., 110, C12002, https://doi.org/10.1029/2004JC002624.

_ , T. Kaminski, M. Karcher, R. Giering, R. Gerdes, and M. Voßbeck, 2009: Adjoint analysis of the 2007 all time Arctic sea-ice minimum. Geophys. Res. Lett., 36, L03707, https:// doi.org/10.1029/2008GL036323.

Kim, J. G., E. C. Hunke, and W. H. Lipscomb, 2006: Sensitivity analysis and parameter tuning scheme for global sea-ice modeling. Ocean Modell., 14, 61-80, https://doi.org/10.1016/ j.ocemod.2006.03.003.

Kim, Y., K. Gotoh, M. Toyosada, and J. Park, 2002: Micro-genetic algorithms ( $\mu \mathrm{GAs})$ for hard combinatorial optimisation problems. ISOPE-I-02-426 2002, Proc. 12th Int. Offshore and Polar Engineering Conf., Kitakyushu, Japan, International Society of Offshore and Polar Engineers, 230-235.

Kimura, N., A. Nishimura, Y. Tanaka, and H. Yamaguchi, 2013: Influence of winter sea ice motion on summer ice cover in the Arctic. Polar Res., 32, 20193, https://doi.org/10.3402/ polar.v32i0.20193.

Köberle, C., and R. Gerdes, 2003: Mechanisms determining the variability of Arctic sea ice conditions and export. J. Climate, 16, 2843-2858, https://doi.org/10.1175/1520-0442(2003) 016<2843:MDTVOA>2.0.CO;2.

Krishnakumar, K., 1989: Micro-genetic algorithms for stationary and nonstationary function optimization, Intel. Control Adaptive Syst., 1996, 289-296.

Kwok, R., G. F. Cunningham, M. Wensnahan, I. Rigor, H. J. Zwally, and D. Yi, 2009: Thinning and volume loss of the Arctic Ocean sea ice cover: 2003-2008. J. Geophys. Res., 114, C07005, https://doi.org/10.1029/2009JC005312. 
Lavergne, T., S. Eastwood, Z. Teffah, H. Schyberg, and L.-A. Breivik, 2010: Sea ice motion from low-resolution satellite sensors: An alternative method and its validation in the Arctic. J. Geophys. Res., 115, C10032, https://doi.org/10.1029/ 2009JC005958.

Lindsay, R., and A. Schweiger, 2015: Arctic sea ice thickness loss determined using subsurface, aircraft, and satellite observations. Cryosphere, 9, 269-283, https://doi.org/10.5194/ tc-9-269-2015.

—, M. Wensnahan, A. Schweiger, and J. Zhang, 2014: Evaluation of seven different atmospheric reanalysis products in the Arctic. J. Climate, 27, 2588-2606, https://doi.org/10.1175/ JCLI-D-13-00014.1.

Massonnet, F., T. Fichefet, H. Goosse, M. Vancoppenolle, P. Mathiot, and C. K. Beatty, 2011: On the influence of model physics on simulations of Arctic and Antarctic sea ice. Cryosphere, 5, 687-699, https://doi.org/10.5194/tc-5-687-2011.

- H. Goosse, T. Fichefet, and F. Counillon, 2014: Calibration of sea ice dynamic parameters in an ocean-sea ice model using an ensemble Kalman filter. J. Geophys. Res. Oceans, 119, 41684184, https://doi.org/10.1002/2013JC009705.

McPhee, M., 2008: Air-Ice-Ocean Interaction: Turbulent Ocean Boundary Layer Exchange Processes. Springer, 216 pp.

Miller, P. A., S. W. Laxon, and D. L. Feltham, 2005: Improving the spatial distribution of modeled Arctic sea ice thickness. Geophys. Res. Lett., 32, L18503, https://doi.org/10.1029/ 2005GL023622.

—, W. L. Laxon, D. L. Feltham, and D. J. Cresswell, 2006: Optimization of a sea ice model using basinwide observations of Arctic sea ice thickness, extent, and velocity. J. Climate, 19, 1089-1108, https://doi.org/10.1175/JCLI3648.1.

—, S. W. Laxon, and D. L. Feltham, 2007: Consistent and contrasting decadal Arctic sea ice thickness predictions from a highly optimized sea ice model. J. Geophys. Res., 112, C07020, https://doi.org/10.1029/2006JD007659.

Nguyen, A. T., D. Menemenlis, and R. Kwok, 2011: Arctic iceocean simulation with optimized model parameters: Approach and assessment. J. Geophys. Res., 116, C04025, https:// doi.org/10.1029/2010JC006573.

Owens, W. B., and P. Lemke, 1990: Sensitivity studies with a sea ice-mixed layer-pycnocline model in the Weddell Sea. J. Geophys. Res., 95, 9527-9538, https://doi.org/10.1029/ JC095iC06p09527.

Pacanowski, R. C., 1995: MOM 2 documentation, user's guide and reference manual. GFDL Ocean Group Tech. Rep. 3.2, Geophysical Fluid Dynamics Laboratory, Princeton Univ., Princeton, NJ, 350 pp., https://www.gfdl.noaa.gov/wp-content/ uploads/2016/10/manual2.2.pdf.

Rothrock, D. A., J. Zhang, and Y. Yu, 2003: The arctic ice thickness anomaly of the 1990s: A consistent view from observations and models. J. Geophys. Res., 108, 3083, https://doi.org/ 10.1029/2001JC001208.

— , D. B. Percival, and M. Wensnahan, 2008: The decline in arctic sea-ice thickness: Separating the spatial, annual, and interannual variability in a quarter century of submarine data. J. Geophys. Res., 113, C05003, https://doi.org/10.1029/ 2007JC004252.

Saha, S., and Coauthors, 2010: The NCEP Climate Forecast System Reanalysis. Bull. Amer. Meteor. Soc., 91, 1015-1057, https:// doi.org/10.1175/2010BAMS3001.1.

_ , and Coauthors, 2014: The NCEP Climate Forecast System version 2. J. Climate, 27, 2185-2208, https://doi.org/10.1175/ JCLI-D-12-00823.1.
Semtner, A. J., 1976: A model for the thermodynamic growth of sea ice in numerical investigation of climate. J. Phys. Oceanogr., 6, 379-389, https://doi.org/10.1175/1520-0485(1976)006<0379: AMFTTG $>2.0 . \mathrm{CO} ; 2$.

Steele, M., R. Morley, and W. Ermold, 2001: PHC: A global ocean hydrography with a high-quality Arctic Ocean. J. Climate, 14, 2079-2087, https://doi.org/10.1175/1520-0442(2001)014<2079: PAGOHW $>2.0$.CO;2.

Stevens, D. P., 1991: The open boundary condition in the United Kingdom fine-resolution Antarctic model. J. Phys. Oceanogr., 21, 1494-1499, https://doi.org/10.1175/1520-0485(1991) $021<1494$ :TOBCIT $>2.0$. CO;2.

Stroeve, J., M. M. Holland, W. Meier, T. Scambos, and M. Serreze, 2007: Arctic sea ice decline: Faster than forecast. Geophys. Res. Lett., 34, L09501, https://doi.org/10.1029/ 2007GL029703.

— , V. Kattsov, A. Barrett, M. Serreze, T. Pavlova, M. Holland, and W. N. Meier, 2012: Trends in Arctic sea ice extent from CMIP5, CMIP3 and observations. Geophys. Res. Lett., 39, L16502, https://doi.org/10.1029/2012GL052676.

Sumata, H., F. Kauker, R. Gerdes, C. Köberle, and M. Karcher, 2013: A comparison between gradient descent and stochastic approaches for parameter optimization of a sea ice model. Ocean Sci., 9, 609-630, https://doi.org/10.5194/ os-9-609-2013.

— T. Tavergne, F. Girard-Ardhuin, N. Kimura, M. A. Tschudi, F. Kauker, M. Karcher, and R. Gerdes, 2014: An intercomparison of Arctic ice drift products to deduce uncertainty estimates. J. Geophys. Res. Oceans, 119, 4887-4921, https://doi.org/10.1002/2013JC009724.

_, R. Kwok, R. Gerdes, F. Kauker, and M. Karcher, 2015a: Uncertainty of Arctic summer ice drift assessed by highresolution SAR data. J. Geophys. Res. Oceans, 120, 52855301, https://doi.org/10.1002/2015JC010810.

_, R. Gerdes, F. Kauker, and M. Karcher, 2015b: Empirical error functions for monthly mean Arctic sea-ice drift. J. Geophys. Res. Oceans, 120, 7450-7475, https://doi.org/ 10.1002/2015JC011151.

— , and Coauthors, 2018: Decorrelation scales for Arctic Ocean hydrography_Part I: Amerasian Basin. Ocean Sci., 14, 161185, https://doi.org/10.5194/os-14-161-2018.

_, F. Kauker, M. Karcher, and R. Gerdes, 2019: Simultaneous parameter optimization of an Arctic sea ice-ocean model by a genetic algorithm. Mon. Wea. Rev., 147, 1899-1926, https:// doi.org/10.1175/MWR-D-18-0360.1.

Szanyi, S., J. V. Lukovich, D. G. Barber, and G. Haller, 2016: Persistent artifacts in the NSIDC ice motion data set and their implications for analysis. Geophys. Res. Lett., 43, 1080010 807, https://doi.org/10.1002/2016GL069799.

Thomas, D. N., and G. S. Dieckmann, 2009: Sea Ice. 2nd ed. WileyBlackwell, $638 \mathrm{pp}$.

Tsamados, M., D. L. Feltham, and A. V. Wilchinsky, 2013: Impact of a new anisotropic rheology on simulations of Arctic sea ice. J. Geophys. Res. Oceans, 118, 91-107, https://doi.org/10.1029/ 2012JC007990.

Tschudi, M. A., C. Fowler, J. A. Maslanik, and J. Stroeve, 2010: Tracking the movement and changing surface characteristics of Arctic sea ice. IEEE J. Sel. Top. Appl. Earth Obs. Remote Sens., 3, 536-540, https://doi.org/10.1109/ JSTARS.2010.2048305.

Ungermann, M., L. B. Tremblay, T. Martin, and M. Losch, 2017: Impact of the ice strength formulation on the performance of a sea ice thickness distribution model in the Arctic. 
J. Geophys. Res. Oceans, 122, 2090-2107, https://doi.org/ 10.1002/2016JC012128.

Uotila, P., S. O'Farrell, S. J. Marsland, and D. Bi, 2012: A sea-ice sensitivity study with a global ocean-ice model. Ocean Modell., 51, 1-18, https://doi.org/10.1016/j.ocemod.2012.04.002. , and Coauthors, 2019: An assessment of ten ocean reanalyses in the polar regions. Climate Dyn., 52, 1613-1650, https:// doi.org/10.1007/s00382-018-4242-z.
Urrego-Blanco, J. R., N. M. Urban, E. C. Hunke, A. K. Turner, and N. Jeffery, 2016: Uncertainty quantification and global sensitivity analysis of the Los Alamos sea ice model. J. Geophys. Res. Oceans, 121, 2709-2732, https://doi.org/10.1002/2015JC011558. Wadhams, P., 2002: Ice in the Ocean. Gordon and Breach, $351 \mathrm{pp}$.

Wunsch, C., 2006: Discrete Inverse and State Estimation Problems. Cambridge University Press, $371 \mathrm{pp}$. 